\title{
Non-uniform porous structures and cycling control for optimized fixed-bed solar thermochemical water splitting
}

\author{
Xiaoyu Dai ${ }^{1}$, Sophia Haussener ${ }^{1, *}$ \\ ${ }^{1}$ Laboratory of Renewable Energy Science and Engineering, EPFL, Station 9, 1015 \\ Lausanne, Switzerland
}

\section{Abstract}

Solar thermochemical redox cycles provide a sustainable pathway for solar fuel processing. If done in porous (ceria) structures, they can profit from faster reaction rates owned to the enhanced heat and mass transport characteristics. However, the exact porous structure and operating conditions significantly affect the performance. We present a transient volumeaveraged fixed-bed model of a thermochemical redox reactor utilizing macroporous ceria. We studied the porosity-dependent $(\varepsilon=0.4-0.9)$ and operating condition-dependent (solar concentration ratio, ratio of oxygen partial pressure to total pressure, gas flow rate) performance of the fixed-bed ceria redox cycle. Structures with large porosity $(\varepsilon=0.9)$ showed better performance than low-porosity structures, owning to the enhanced heat absorption and resulting higher temperatures. We show that the cycle duration requires optimization according to the porosity of the structure. Two hours of operation for a structure with $\varepsilon=0.75$ resulted in the largest hydrogen production $\left(115.78 \mathrm{~mL} \mathrm{~g}_{\text {ceria }}^{-1}\right)$ if the single cycle duration was 240 s (i.e. 30 cycles in 2 hours), while nearly five times less was produced for a 15 times longer single cycle duration (i.e. 2 cycles in 2 hours). We subsequently introduced porous structures with different types of non-uniform porosity distributions. For an average porosity of $\varepsilon=0.75$, the most favorable non-uniform porosity media exhibited higher porosity at the boundaries and a denser core. The fuel production of the best non-uniform porous structure was six times larger compared to a uniform porous structure. Adjusting on top of this the cycling conditions, a 14.6 times production gain was achieved. This work suggests that under non-isothermal operation condition for macroporous ceria redox fixed-bed cycling, non-uniform porous structure with higher porosity boundaries and a dense core benefit fuel production and porosity-dependent cycle duration modulation can be used to increase performance.

\section{Introduction}

Solar thermochemical redox cycles can produce hydrogen and carbon monoxide from water and $\mathrm{CO}_{2}$, utilizing metal oxides that are repeatedly reduced and oxidized. The reduction step is a high-temperature endothermic reaction where solar irradiation provides

\footnotetext{
*Corresponding author: sophia.haussener@epfl.ch
} 
the energy and heat to drive the reaction (eq. (1)). The oxides are (non-stoichiometrically) reduced to create oxygen vacancies and release gaseous oxygen. The fully oxidized ceria has the ideal cubic fluorite crystal structure. With increased temperature, Ce changes the oxidation state. The created oxygen vacancies are balancing the resulting charge difference. The extent of oxygen vacancy is depicted by $\delta .[1,2]$ In the subsequent step, the oxygen vacancy is refilled by the oxygen from the water, Ce is back to the previous state. This lower temperature exothermic reaction (eq. (2)) uses water (and/or $\mathrm{CO}_{2}$ ) as oxidant to reoxide the metal oxide and produce hydrogen (and/or CO). Overall, the net result is the splitting of the water into hydrogen and oxygen, in spatially and temporally separated steps. $\mathrm{CeO}_{2} \rightarrow \mathrm{CeO}_{2-\delta}+\frac{\delta}{2} \mathrm{O}_{2}$

$\mathrm{CeO}_{2-\delta}+\delta \mathrm{H}_{2} \mathrm{O} \rightarrow \mathrm{CeO}_{2}+\delta \mathrm{H}_{2}$

The hydrogen yield of the oxidation reaction is determined by the oxygen vacancy $(\delta)$, created in the reduction reaction. The reference redox material for this process is ceria, owned to its non-volatile process, non-stoichiometric structure, abundant storage, and relatively fast reaction kinetics. $[1,3,4]$

The solar-to-fuel efficiency of the thermochemical cycles can - in theory - reach 20-35\% [5] while experimental demonstration have achieved single digit efficiencies only. [6,7] The discrepancy between experimental demonstration and theoretical limits raises from the large (radiative) heat losses and the thermodynamically limited oxygen release capability of ceria. [2,8-10]

The stability of the thermochemical cycles has been demonstrated over hundreds of cycles, almost identical behavior has been observed in each individual cycle, allowing for studying the effect of cyclic duration. [6,11-13] Single cycling time and the duration fraction of reduction and oxidation are essential factors influencing the overall solar-to-fuel efficiency. Venstrom et al. and Davenport et al. studied the isothermal thermochemical cycle for splitting of $\mathrm{CO}_{2}$ and $\mathrm{H}_{2} \mathrm{O}$, respectively. [14-17] They found that shorter cycle duration will lead to higher efficiency under the isothermal and fixed flow rate conditions. Furthermore, the fraction of reduction and oxidation within a single-cycle should not be less than $30 \%$ to maintain a high yield.

Typically, the implementation of solar thermochemical redox cycles involves a solar reactor consisting of a solar cavity and reaction chamber, which includes reactive ceria that is incorporated as porous media. Efforts aiming at improving the performance of the solar thermochemical redox cycles focus on both scales, the reactor-scale and porous mediascale. On the reactor scale, multiple reactor design concepts have been proposed. Diver at al. designed a novel concept of reactor, CR5, that is composed of counter-rotating disks which act as solar receiver, chemical reactor and heat recuperator. The reactor has been fabricated and tested at Sandia National Laboratories. [18] The rotating disk design enables continuous irradiation and reaction. Its integrated heat recuperation is one of the reason 
that helps to reach a thermal efficiency of $32.2 \%$. Roeb et al. at DLR proposed a volumetric porous reactor. The solar irradiation impinged on the front side of honeycomb reactive material through a quartz window. [19] Furler et al. proposed a conically shape cavity with secondary concentrator, enabling more uniform distribution of the incoming radiation. This new reactor design realized an 5.4\% solar-to-fuel efficiency. An improvement of $86 \%$ in the solar-to-fuel efficiency (compared to cylindrical cavity) resulted from lower radiation and conduction losses, more uniform temperature distribution, and higher mass loading of the reactive material. [20] Bader et al. presented a tubular reactor for continuous fuel production via ceria isothermal redox cycling. [21] The multi-tube configuration (in which the reactive porous ceria was filled into the tubes) extended the reactive area compared to one single piece structure, and the thin tube wall and large porosity facilitated the fast heat and mass transfer, allowing to achieve low temperature and pressure gradients within the porous material.

On the porous material scale, improvements in efficiency have been achieved by doping the material with $\mathrm{Li}, \mathrm{Cu}, \mathrm{Mg}, \mathrm{Co}$ and other reactive metal cations. [22,23] This approach enlarges the oxygen storage ability and increases the reduction kinetics, all attributed to the small ionic radius and high valence of the dopant. Since the Coulombic forces between the oxygen ions and cations are proportional to the charges and reversed to the ionic radius, the $\mathrm{Ce}-\mathrm{O}$ bonds within such doped ceria tend to break more easily. Specifically, the addition of $2.5 \%$ of Li into ceria increased the hydrogen and oxygen production rates by $271 \%$ compared to pristine ceria [24], or $10 \%$ of $\mathrm{Mg}$ increased the hydrogen oxygen production rates by $10 \%$ while also increasing the bulk conductivity. [25]

Apart from the doping, more oxygen vacancies could be created by introducing active cations or by modifying the macroporous structure of the porous media. It has been demonstrated that a tailored design of the macroporous structure of ceria can shorten the gas diffusion length and extend the interfacial surface area, both improving the heat and mass transport and, consequently, the fuel yield. [22,23] Various types of macroporous ceria types have been studies. Furler et al. used fibrous ceria for syngas production with a solar-to-hydrogen efficiency of $0.15 \%$. They observed that the low efficiency resulted from the small mass loading and weak conductive heat transfer, the latter caused an inhomogeneous temperature distribution within the reactor. [11] Three-dimensionally ordered macro-porous (3DOM) ceria samples were investigated by Venstrom et al. with significantly improved production rates as a result of the high specific area. [26] Reticulate porous ceria (RPC) structures showed, so far, the best reactor efficiencies [20], mostly associated to volumetric light absorption and deeper penetration of the radiation. RPC led to a 17 times higher solar-to-fuel efficiency than the felt. [11,27] Takacs et al. fabricated and tested various porosities and pore sizes of reticulate porous structures, observing that the heat transfer was favored for samples with larger pore sizes and the yield was highest with high porosity samples. [28] 
In heterogeneous porous media, due to the large irradiation magnitudes, temperatures in the fluid and solid phase are not equal and vary with location and time. [9,10,29-31] Local thermal non-equilibrium needs to be considered in the analysis. Keene et al. formulated a 1D dynamic macroscopic model describing the thermal reduction process of ceria in an axisymmetric cylindrical domain. [10,29] Bala Chandran et al. expanded the model and applied it to a three-dimensional tubular cavity. [32] Ackermann et al. developed a similar 1D transient model accounting for ceria's specific dual-scale porous structure, utilizing a Monte-Carlo ray-tracing method to predict the absorbed radiation. [9]

Instead of homogenous porous media, Roldan et al. proposed a changing porosity distribution to improve the solar radiation absorption. [33] The idea of changing the porosity distribution has been proved to have impact on the heat and mass transfer in nonsolar applications. For example, a functionally graded metallic foam significantly improved the heat insulation performance. [34] For designing a polymer-electrolytemembrane fuel cell, liquid water discharges more from the catalyst layer into the gas channel within gradient-porosity gas diffusion layers. [35,36] Ackermann et al. applied variable porosity media in ceria-assisted solar thermochemical redox cycling. For an identical global porosity of 0.75 , a RPC with smaller pore sizes in the front $(\sim 0.6 \mathrm{~mm})$ and larger pore size in the back $(\sim 2.2 \mathrm{~mm})$ showed a peak efficiency of $0.9 \%$ compared to the one of single pore size $(0.6 \mathrm{~mm}$ or $2.2 \mathrm{~mm})$ with a peak efficiency of only $0.7 \%$. The gain in efficiency was due to the reduced radiation losses at the backside. [9] A different series of hierarchically ordered porous ceria structures with a porosity gradient were fabricated by Hoes et al. [34] using the replica method. Four different structures (cube, pyramid, honeycomb and V-groove) were constructed of unit cells with decreasing cell sizes in the direction of incident radiation. A more uniform temperature distribution was found for those gradient porous samples in contrast to the uniform RPC, leading to a superior oxygen release performance. Haeussler et al. [13] also proposed graded porous configuration inside a cylindrical cavity. Their reactive porous structure was composed of 4 rings with smaller cell density (larger cell size) on the top and 1 disk with larger cell density (smaller cell size) on the bottom. The increasing cell density from the top to the bottom was expected to enhance the optical thickness and reduce the radiation diffusion, which resulted in larger temperature gradients within the foam and along the axial direction. The gradient porous foam did not alter substantially the fuel production, attributed to the similar average reduction temperature.

The effect of non-uniform porous structure on the heat and mass transfer in solar thermochemical reactors is still ambiguous. Besides, limited efforts have been made to analyze the dynamic cycling performance for structures with variable porosity. Herein, we present a study which focuses on the effect of morphology on the fuel yield during the dynamic reaction steps and analyzes the porosity-dependent cycle performance. A onedimensional transient model of a solar thermochemical redox reactor is built for a complete solar-driven ceria-assisted water-splitting cycle. In addition to uniform porosity structures, 
we propose several different configurations with variable porosity distribution and different duration length for the cycling operation. The temperature and fuel production profiles are investigated with following objectives: i) to understand the effect of variable uniform porosity on the fuel production, ii) to see how the operation conditions influence the energy conversion process and determine appropriate sets of conditions, iii) to investigate the non-uniform structure that favors or hinders the reduction, and iv) to explore the effect of cycling control on the fuel production.

\section{Methodology}

\subsection{Model and assumption}

The simulation domain consists of an axisymmetric cylindrical reactor filled with macroporous ceria, the schematic is shown in Figure 1. We build a one-dimensional transient computational model accounting for coupled heat and mass transfer as well as chemical reaction. The reactor is a $1 \mathrm{D}$ slab with $10 \mathrm{~mm}$ thickness, $L .[10]$ The volume-averaging approach was used and the information of the porous structure is incorporated through effective heat and mass transport properties.

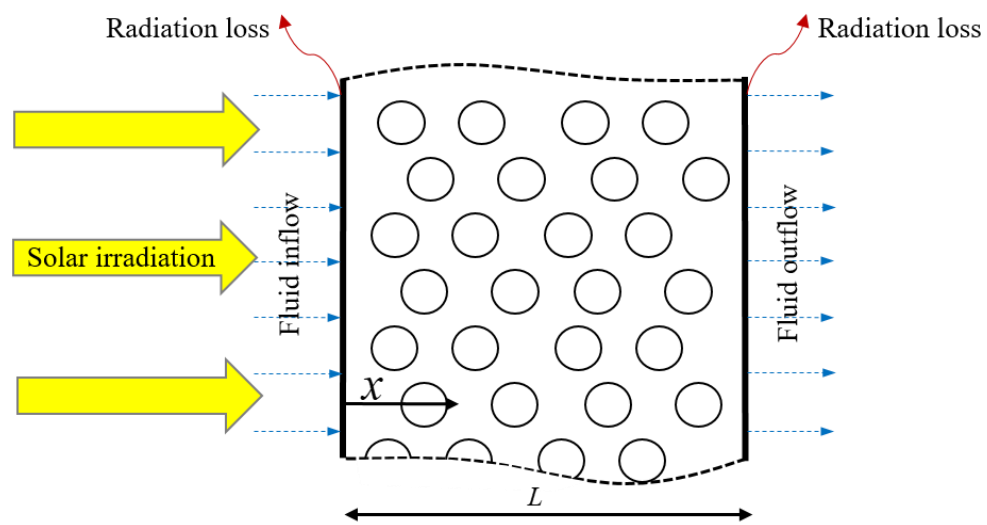

Figure 1. Schematic of the 1D slab reactor geometry with solar irradiation direction in parallel with the fluid flow. Inside, the reactor is filled macroporous ceria.

During the reduction step, the reactor's inlet boundary is exposed to concentrated solar radiation. A preheated flow of a mixed fluid, composed of argon and residual quantities of oxygen, enters the reactor from the front and parallel to the irradiation direction. The product stream is leaving the reactor at the backside and at atmospheric pressure. The irradiation is removed in the following oxidation step, and the composition of the fluid at the inlet is switched to argon and water vapor.

Some assumptions are applied in the following modeling work: i) the physical properties of the macroporous material are isotropic and stable over cycling, ii) the temperature of the inlet mixture is equal to the surrounding temperature, iii) the mixed gas within the reactor is ideal and radiatively non-participating, iv) the solid porous ceria is a radiatively 
participating medium, and v) the topside and backside surface of the reactor are grey and diffuse.

The species temperature-dependent viscosity, thermal conductivity, and specific heat are evaluated based on previous literature.[37-40] The properties of the gas mixture are obtained by a mole fraction-weighted average. [41] The mass diffusion coefficient is calculated using the Chapman-Enskog theory. $[38,42]$

\subsection{Morphological characterization}

We assume the reactive material to be a reticulate porous foam, such as the one investigated by Suter et al. [43] Specifically, Suter et al. use a tomography-based method to characterize the heat and mass transport in the porous foam, followed by estimating the change in the transport as a function of change in porosity only. For a macroscopically isotropic and homogeneous porous sample, the porosity distribution is homogeneous everywhere along the $x$-axis. The mean pore diameter $d_{\text {mean }}$ and specific surface area $A_{0}$ can both be expressed as a function of porosity only:

$$
\begin{aligned}
& d_{\text {mean }}=2.20 \times 10^{-3} \times \varepsilon+7.59 \times 10^{-4} \\
& A_{0}=A_{\text {interface }} / V=-2277.8 \times \varepsilon^{2}+2533 \times \varepsilon+262.3
\end{aligned}
$$

For a macroscopically isotropic but inhomogeneous porous sample, the porosity varies as a function of the local position $x$ (see Figure 2). We propose linear, parabolic, and exponential functions and their axisymmetric variations (see Table 1). All functions incorporate a gradient $k$, which indicates the degree of porosity variation with respect to $x$. With the constraint that the total mass loading is the same as for the reference uniform porous case (i.e. the integral of all the non-uniform distribution function is equal to $L \varepsilon_{\text {average }}$ ) and the porosity is bound to $(0,1)$, there are limits for the gradient $k$ for each function. As in reality the porosity cannot be equals to 0 or 1 , we cut of the top and bottom $10 \%$ of the $k$-range, leading to the realistic $k$-range shown in Table 1 . We choose the reference case of average porosity $\varepsilon_{\text {average }}=0.75$ in the current study, the reason for this choice is given in the section 4.1.
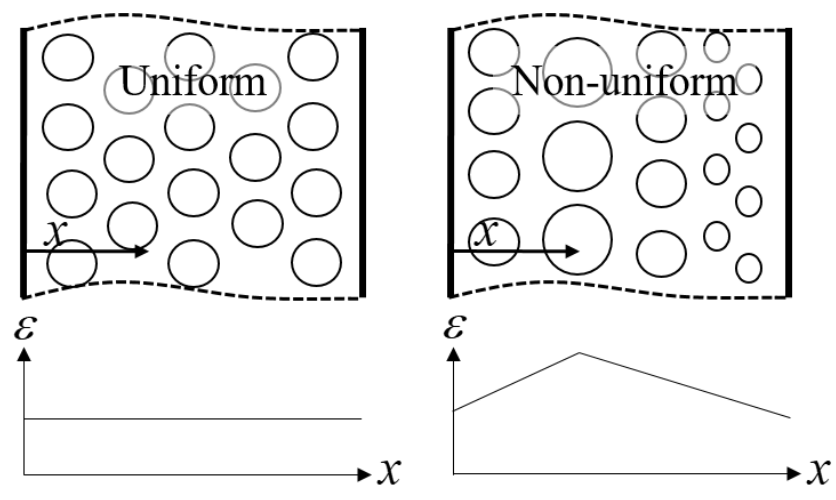

Figure 2. Sketch of uniform (left side) and non-uniform (right side) porous media, including a location dependent sketch of the porosity, $\varepsilon(x)$. 
Employing the non-uniform distribution functions, we obtain the corresponding porositydependent non-uniform mean pore diameter and specific surface area:

$$
\begin{aligned}
& d_{\text {mean }}(x)=2.20 \times 10^{-3} \times \varepsilon(x)+7.59 \times 10^{-4} \\
& A_{0}(x)=A_{\text {interface }}(x) / V=-2277.8 \times \varepsilon(x)^{2}+2533 \times \varepsilon(x)+262.3
\end{aligned}
$$

Table 1. List of non-uniform porosity distribution functions and the corresponding available range for gradient $k$

Porosity distribution function

$$
\begin{aligned}
& f_{0}: \varepsilon(x)=\varepsilon_{\text {average }} \\
& f_{1}: \varepsilon(x)=\varepsilon_{\text {average }}+k \times(x-L / 2) \\
& f_{2}: \varepsilon(x)=\varepsilon_{\text {average }}+k \times(|x-L / 2|-L / 4) \\
& f_{3}: \varepsilon(x)=\varepsilon_{\text {average }}+k \times\left(x^{2}-L^{2} / 3\right) \\
& f_{4}: \varepsilon(x)=\varepsilon_{\text {average }}+k \times\left((x-L / 2)^{2}-L^{2} / 12\right) \\
& f_{5}: \varepsilon(x)=\varepsilon_{\text {average }}+k \times\left(e^{x}-\left(e^{L}-1\right) / L\right) \\
& f_{6}: \varepsilon(x)=\varepsilon_{\text {average }}+k \times\left(e^{|x-L / 2|}+2\left(1-e^{L / 2}\right) / L\right)
\end{aligned}
$$

\subsection{Effective heat and mass transport properties}

The macroscopic effective heat and mass transport properties, computed directly based on the pore-scale structure and given in literature, were applied. [43-45] Those effective properties will be implemented into the volume-averaging transport equations to resolve the desired state function. The empirical porosity-dependent correlations are presented in Table 2.

Table 2. List of porosity-dependent correlation of effective heat and mass transport properties.

Effective transport properties Porosity-dependent functions

\begin{tabular}{ll}
\hline Permeability & $K(x)=\varepsilon(x)^{3.5} /\left(4.81 \times A_{0}(x)^{2}\right)$ \\
Dupuit-Forchheimer & $F(x)=9.81 \times 10^{-6} / K(x)^{1.12}$ \\
coefficient & \\
Tortuosity & $\tau(x)=l_{\text {path }} / l_{\text {sample }}=1+8.63 \times 10^{-1} \times(1-\varepsilon(x))$ \\
Convection & $\mathrm{Nu}(x)=5.54+\left(0.71 \times \varepsilon(x)^{2}-0.63 \times \varepsilon(x)+\right.$ \\
& $0.29) \mathrm{Re}^{\sqrt{1.7-1.39 \times \varepsilon(x)}} \operatorname{Pr}^{0.6}$ \\
Thermal conductivity & $\frac{k_{e}(x)}{k_{s}}=\left(1-\sqrt{(0.75-0.83 \times \varepsilon(x))} \frac{k_{f} / k_{s}}{\varepsilon(x)+(1-\varepsilon(x)) k_{f} / k_{s}}+\right.$ \\
& $\sqrt{0.75-0.83 \times \varepsilon(x)}\left(\varepsilon(x) \frac{k_{f}}{k_{s}}+(1-\varepsilon(x))\right.$ \\
& $\beta(x)=1.77 \times(1-\varepsilon(x)) / d_{\text {mean }}(x)$
\end{tabular}




\subsection{Governing conservation equations}

\subsubsection{Mass conservation}

The mass conservation for the solid phase includes a production term on the RHS resulting from the oxygen release or capture during the reduction or oxidation step, respectively:

$$
\frac{\partial(1-\varepsilon(x))\left\langle\rho_{\mathrm{s}}\right\rangle}{\partial t}=r_{o_{2}}
$$

Where $\left\langle\rho_{\mathrm{s}}\right\rangle$ is the volume-averaging solid ceria density, $r_{o_{2}}$ is the $\mathrm{O}_{2}$ production or consumption rate. The mass conservation equation for the fluid phase $\mathrm{O}_{2}$ during reduction is:

$$
\frac{\partial \varepsilon(x)\left\langle\rho_{\mathrm{f}}\right\rangle}{\partial t}+\nabla \cdot\left(\varepsilon(x)\left\langle\rho_{\mathrm{f}}\right\rangle\langle u\rangle\right)=r_{o_{2}}
$$

Where $\left\langle\rho_{\mathrm{f}}\right\rangle$ represents the volume-averaging fluid density $\langle u\rangle$ is the fluid flow velocity. The fluid flow is considered as incompressible and laminar.

\subsubsection{Energy conservation}

Following the non-thermal equilibrium assumption, the governing energy conservation equations of the solid and fluid phases were modeled separately. The solid phase version incorporates conductive, radiative, and convective heat transfer, and a reaction term:

$$
\frac{\partial}{\partial t}(1-\varepsilon(x))\left\langle\rho_{\mathrm{s}}\right\rangle\left\langle C_{\mathrm{ps}}\right\rangle\left\langle T_{\mathrm{s}}\right\rangle=\nabla \cdot\left(k_{\mathrm{e}}(x) \nabla\left\langle T_{\mathrm{s}}\right\rangle\right)+\left\langle\nabla \cdot q_{\mathrm{rad}}\right\rangle+h_{\mathrm{sf}} A_{\mathrm{sf}}\left(\left\langle T_{\mathrm{f}}\right\rangle-\left\langle T_{s}\right\rangle\right)+Q_{\text {reaction }}
$$

Where $\left\langle C_{\mathrm{ps}}\right\rangle$ is the volume-averaging solid specific heat, $Q_{\text {reaction }}$ represents the heat sink or source generated by the chemical reaction during two steps. The radiation source term $\nabla \cdot q_{\text {rad }}$ is calculated by the P-1 model and only appears during the reduction process $[46,47]$ :

$$
\begin{aligned}
& -\nabla \cdot\left(\frac{1}{3 \beta(x)} \nabla G\right)=\kappa(x)\left(4 \sigma_{B}\left\langle T_{s}\right\rangle^{4}-G\right)+\sigma(x) G_{c} \\
& G_{c}=-q_{\text {in }} \exp \left(-\int \beta(x) d x\right) \\
& \left\langle\nabla \cdot q_{\mathrm{rad}}\right\rangle=\kappa(x)\left(4 \sigma_{B}\left\langle T_{s}\right\rangle^{4}-G_{c}\right)
\end{aligned}
$$

Where $\kappa(x)$ and $\sigma(x)$ are the absorption and scattering coefficients, respectively.

The energy conservation for the fluid phase lacks the radiation term, as a result of assumption of radiatively non-participating gas:

$$
\frac{\partial}{\partial t}\left(\varepsilon(x)\left\langle\rho_{\mathrm{f}}\right\rangle\left\langle C_{\mathrm{pf}}\right\rangle\left\langle T_{\mathrm{f}}\right\rangle\right)+\nabla \cdot\langle u\rangle\left\langle\rho_{\mathrm{f}}\right\rangle\left\langle C_{\mathrm{pf}}\right\rangle\left\langle T_{\mathrm{f}}\right\rangle=\nabla \cdot\left(\varepsilon(x)\left\langle k_{\mathrm{f}}\right\rangle \nabla\left\langle T_{\mathrm{f}}\right\rangle\right)+h_{\mathrm{sf}} A_{\mathrm{sf}}\left(\left\langle T_{\mathrm{s}}\right\rangle-\left\langle T_{\mathrm{f}}\right\rangle\right)
$$

\subsubsection{Momentum conservation}

The flow through the porous media is modeled by the Darcy-Brinkman-Forchheimer model. Applied to the present problem, it yielded:

$\frac{\partial}{\partial t}\left(\varepsilon(x)\left\langle\rho_{\mathrm{f}}\right\rangle\langle u\rangle\right)+\nabla \cdot\left(\varepsilon(x)\left\langle\rho_{\mathrm{f}}\right\rangle\langle u\rangle \cdot\langle u\rangle\right)=-\nabla\langle p\rangle-\frac{\left\langle\mu_{\mathrm{f}}\right\rangle}{K}\langle u\rangle-F_{\mathrm{D}}\left\langle\rho_{\mathrm{f}}\right\rangle\langle u\rangle \cdot\langle u\rangle$ 
Where $p$ is the pressure of the fluid, $\mu_{\mathrm{f}}$ is the dynamic viscosity of the fluid.

\subsubsection{Species transport}

The species transport equation for $i\left(i=\mathrm{O}_{2}, \mathrm{Ar}\right.$ for the reduction step and $i=\mathrm{H}_{2}, \mathrm{H}_{2} \mathrm{O}, \mathrm{Ar}$ for the oxidation step) of the fluid phase considers the accumulation of species $i$ in the control volume, convective and diffusive transport, and species evolution by chemical reactions:

$$
\frac{\partial \varepsilon(x)\left\langle\rho_{\mathrm{f}}\right\rangle\left\langle Y_{i}\right\rangle}{\partial t}+\nabla \cdot\left(\varepsilon(x)\langle u\rangle\left\langle\rho_{\mathrm{f}}\right\rangle\left\langle Y_{i}\right\rangle\right)=\nabla \cdot\left(\varepsilon(x) D_{i} \nabla\left(\left\langle\rho_{\mathrm{f}}\right\rangle\left\langle Y_{i}\right\rangle\right)\right)+r_{i}, i=\mathrm{O}_{2}, \mathrm{H}_{2}, \mathrm{H}_{2} \mathrm{O}, \mathrm{Ar}
$$

Where $Y_{i}$ and $D_{i}$ is the mass fraction and gas diffusion coefficient of species $i$.

\subsubsection{Initial and boundary conditions}

The initial mass flow rate and temperature of the inflowing gas at the front side entry of the reactor are specified, $\left.\rho u\right|_{t=0}=\rho u_{\text {in }},\left.T_{\mathrm{f}}\right|_{t=0}=T_{\text {f,in }}$. The pressure at the backside outlet is set as ambient pressure. The radiative heat loss at the inlet and outlet boundary are determined by $q_{\mathrm{rad} \mathrm{loss}}=(1-\varepsilon(x)) e \sigma_{B}\left(T_{\mathrm{s}}^{4}-T_{\text {amb }}^{4}\right) \cdot[9,10,30]$

\subsection{Chemical reaction kinetics}

In the two-step ceria redox reactions, the reduction rate is limited by thermodynamics rather than material kinetics $[16,48]$. The correlation between nonstoichiometry in ceria, oxygen partial pressure, temperature, enthalpy, and entropy has been derived by Paneler et al. and is represented by eq. (16). [2] For the oxidation step, the reaction regime depends on the temperature range: above $\sim 1273 \mathrm{~K}$, the reaction is controlled by the supplied gas rate, i.e. thermodynamics; below $\sim 1273 \mathrm{~K}$, the reaction rate is hindered by the surface kinetics [16]. Here based on the numerical reaction model developed by Keene et al. and Chandran et al., we employ the rate expressed as a function of the kinetic rate constants $n_{\text {red }}$ or $n_{\text {oxi }}$ for reduction and oxidation, respectively. $[10,32]$ The kinetic rate is obtained by fitting the data with experimental data in literature $[17,48,49]$.

$\ln \left(P_{\mathrm{O}_{2}}(\delta, T)\right)=\frac{-\Delta H_{\mathrm{red}}(\delta)+T_{\mathrm{s}} \Delta S_{\text {red }}(\delta)}{R T_{\mathrm{s}}}$

\subsubsection{Reduction reaction}

The single ionized and double ionized $\mathrm{O}_{2}$ reaction rates are expressed by eqs. (17) and (18), respectively. An oxygen vacancy can be singly or doubly ionized, dependent on the oxidation state of cerium atoms. When the oxygen vacancy is singly ionized, a single cerium atom in its $3+$ oxidation state will release an oxygen atom. If the oxygen vacancy is doubly ionized, two cerium atoms in their 3+ oxidation state will release a single oxygen atom.[10,29] At the thermodynamic limit, to find the appropriate kinetic constant $n_{\text {red }}$ for the reduction reaction, a set of parametric values is compared to the thermodynamic limit. $[14,17]$ As shown in Figure 3a, the doubly ionized model with a rate constant of 
$n_{\mathrm{red}}=10^{-3}\left[\mathrm{~mol} \mathrm{~m}^{-2} \mathrm{~s}^{-1}\right]$ showed the minimum relative error compared to the experimental data.

$$
\begin{aligned}
& r_{\mathrm{O}_{2}}=\frac{A_{0} M_{\mathrm{O}_{2}}}{2} n_{\mathrm{red}}\left[\exp \left(\frac{-\Delta H_{\mathrm{red}}(\delta)+T_{\mathrm{s}} \Delta S_{\mathrm{red}}(\delta)}{2 R T_{\mathrm{s}}}\right) \delta^{2}-\left(\frac{p_{\mathrm{O}_{2}}}{p_{\text {ref }}}\right)^{1 / 2} \delta^{2}\right] \\
& r_{\mathrm{O}_{2}}=\frac{A_{0} M_{\mathrm{O}_{2}}}{2} n_{\mathrm{red}}\left[\exp \left(\frac{-\Delta H_{\mathrm{red}}(\delta)+T_{\mathrm{s}} \Delta S_{\mathrm{red}}(\delta)}{2 R T_{\mathrm{s}}}\right) \delta^{3}-\left(\frac{p_{\mathrm{O}_{2}}}{p_{\text {ref }}}\right)^{1 / 2} \delta^{3}\right]
\end{aligned}
$$

a.

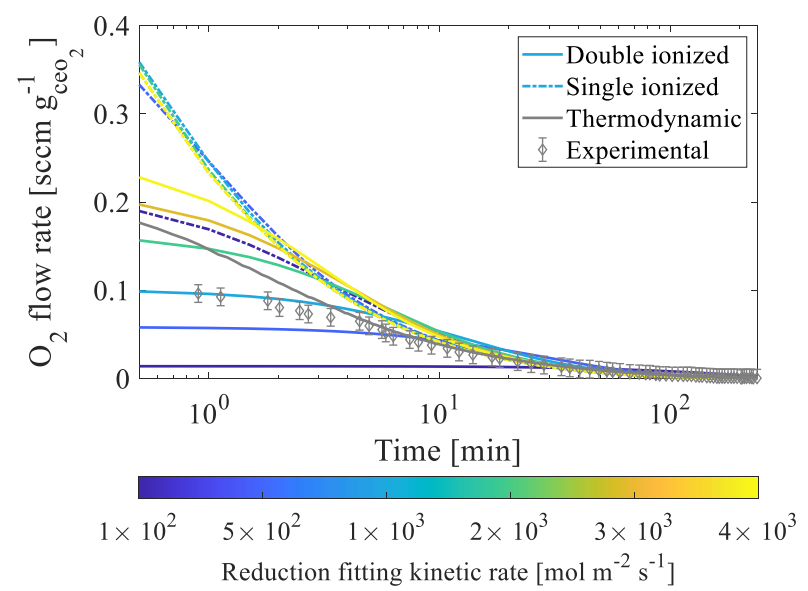

b.

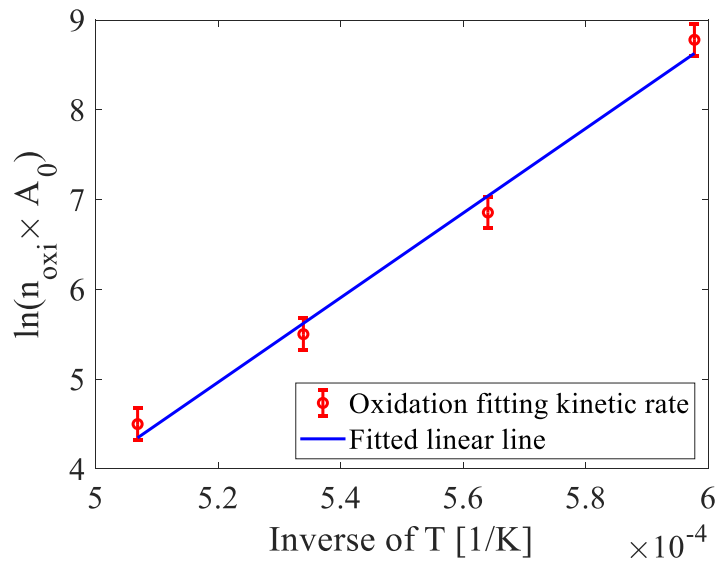

Figure 3. a) Oxygen production rate as a function of time for different kinetic fitting models and varying reduction kinetic constants. Experimental data and isothermal thermodynamic model data are from $[17,48]$. Single ionized and double ionized reaction models are evaluated. b) The logarithm of the product of oxidation kinetic constant and specific surface area is shown as a function of the inverse of temperature for the isothermal oxidation reaction. [16,49]

\subsubsection{Oxidation reaction}

The rate expression for hydrogen and water in the oxidation process was derived in the same way, i.e. by applying the law of mass action as presented in eqs. (19) and (20), according to the required Gibbs free energy and equilibrium constant for the occurrence of oxidation reaction. [10,49] In the oxidation rate expression, similar to the reduction rate expression, a constant parameter - defined as the oxidation rate parameter - was introduced and related to the kinetics of the reaction.[49] For oxidation temperatures above 1273K, the oxidation reaction should be limited by thermodynamics. $[16,48]$ We observed that it was not possible to describe the correct rate expression with a single rate constant. Inspired by the model proposed by Bulfin et al. and Bala Chandran et al., the equation's oxidation rate parameter was formulated as a function of temperature and reacting surface area. $[31,50,51]$ Figure $3 \mathrm{~b}$ shows that the kinetic rate constant is temperature dependent, and the logarithm of the product of oxidation kinetic constant and specific surface area is linearly proportional to the inverse of temperature for an isothermal oxidation reaction. The oxidation rate constant is formulated by eq. (21) by comparing the kinetic rate to the isothermal thermodynamic rate under the same operating condition. [49] 


$$
\begin{aligned}
& r_{\mathrm{H}_{2}}=-A_{0} M_{\mathrm{H}_{2}} n_{\text {oxi }}\left[\exp \left(\frac{\Delta G_{\mathrm{H}_{2} \mathrm{O}}+\frac{1}{2}\left(-\Delta H_{\mathrm{red}}(\delta)+T_{\mathrm{s}} \Delta S_{\text {red }}(\delta)\right)}{R T_{\mathrm{s}}}\right)\left(\frac{p_{\mathrm{H}_{2}}}{p_{\text {ref }}}\right) \delta^{3}-\left(\frac{p_{\mathrm{H}_{2} \mathrm{O}}}{p_{\text {ref }}}\right) \delta^{3}\right] \\
& r_{\mathrm{H}_{2} \mathrm{O}}=A_{0} M_{\mathrm{H}_{2} \mathrm{O}} n_{\text {oxi }}\left[\exp \left(\frac{\Delta G_{\mathrm{H}_{2} \mathrm{O}}+\frac{1}{2}\left(-\Delta H_{\text {red }}(\delta)+T_{\mathrm{s}} \Delta S_{\text {red }}(\delta)\right)}{R T_{\mathrm{s}}}\right)\left(\frac{p_{\mathrm{H}_{2}}}{p_{\text {ref }}}\right) \delta^{3}-\left(\frac{p_{\mathrm{H}_{2} \mathrm{O}}}{p_{\text {ref }}}\right) \delta^{3}\right] \\
& n_{\text {oxi }}=2.9023 \times 10^{-6} \exp \left(\frac{3.9161 \times 10^{5}}{R T_{\mathrm{s}}}\right) / A_{0}
\end{aligned}
$$

\subsection{Numerical procedure and model validation}

The 1D transient volume-averaged mass, energy, momentum, and species conservation equations are solved with a commercial CFD solver (COMSOL 5.3). A mesh independence study indicated that a mesh element size of $0.01 \mathrm{~mm}$, uniformly distributed along the reactor axis was sufficient to provide a mesh-independent result. A segregate-transient solver is used to solve the governing equations. Convergence is reached when the variable residuals difference is smaller than $10^{-6}$. To validate our model, we compared the results from the current model to the data from Keene et al. [10] At the same condition, the maximum relative error between the calculated results and their data was $1 \%$.

\section{Results and discussion}

In this section, the effects of uniform porosity, operational condition, cycle duration, and non-uniform porosity distribution on the fuel yield were investigated. A series of operational conditions are evaluated: the solar irradiation concentration ratio $C=300,600$, $750[-]$, inflow mass flow rate $\rho u=0.003,0.03,0.3\left[\mathrm{~kg} \mathrm{~m}^{-2} \mathrm{~s}^{-1}\right]$, and initial oxygen partial pressure fraction (i.e. ratio between oxygen partial pressure and total pressure) of the fluid mixture at the inlet $P_{\mathrm{O}_{2}}=10^{-6}, 10^{-5}, 10^{-4}$ [-]. The inflow fluid temperature is $1273 \mathrm{~K}$ (preheated), which remained for all cases. During the oxidation, the inlet mixture is composed of 50wt $\%$ water vapor and $50 \mathrm{wt} \%$ argon entering at ambient temperature and a flow rate of $\rho u=0.03\left[\mathrm{~kg} \mathrm{~m}^{-2} \mathrm{~s}^{-1}\right]$.

\subsection{Effect of porosity}

A wide range of macroporous ceria structures with porosities varying from 0.4 to 0.9 are evaluated for their fuel production amount and average solid temperature during one complete cycle composed of 30 minutes of reduction and 30 minutes of oxidation. We performed a rather long reduction time to ensure full reduction. The identical choice of reduction and oxidation duration was to guarantee the completion of re-oxidation even though the oxidation reaction is usually faster than the reduction. [16,48] This 0.5 fraction of total cycling time allotted to reduction is in the favorable range as estimated by Venstrom 
et al. and Davenport et al. $[14,15]$ Constraint by the unchanged reactor dimension, the total reacted mass of porous ceria decreases with the increasing porosity from 0.4 to 0.9 . The operating conditions chosen are $C=750, \rho u=0.03 \mathrm{kgm}^{-2} \mathrm{~s}^{-1}$, and $P_{\mathrm{O}_{2}}=10^{-5}$. Figure 4 represents the fuel yield by unit gram of ceria, eliminating the effect of mass loading. Under continuous solar irradiation, the temperature rapidly increases to steady state (within 100 s) while the integral of generated oxygen amount increases more slowly. The derivative of cumulative $\mathrm{O}_{2}$, which represents the oxygen generation rate, raises sharply at the initial stage (maximal generation rate is $0.033 \mathrm{~mL} \mathrm{~s}^{-1} \mathrm{~g}_{\text {ceria }}^{-1}$ ) and then slows down, approaching zero while the solid ceria is maintained at a constant, high temperature.

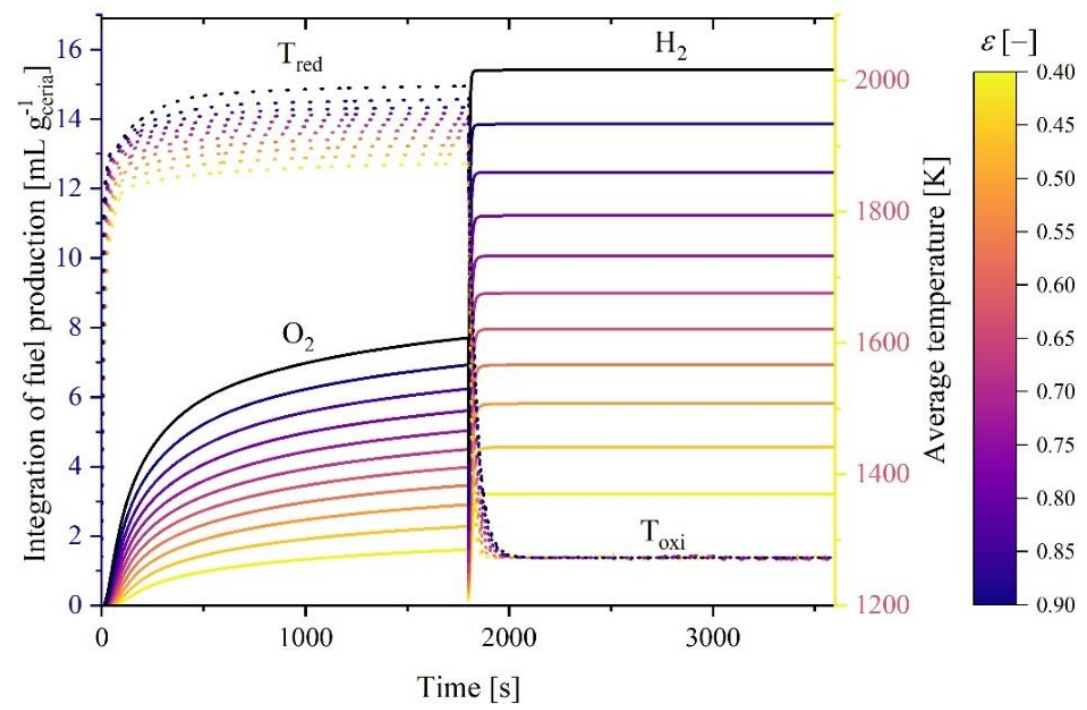

Figure 4. Evolution of porosity-dependent fuel generation (solid lines) and average solid temperature (dotted lines) as a function of operational time for a complete cycle composed of reduction and oxidation steps (both taking $30 \mathrm{~min}$ ).

For the ceria with porosity $\varepsilon=0.9$, we observed that the average solid temperature achieved a maximum of $1991 \mathrm{~K}$, and the total oxygen amount was the highest and equals to $7.7 \mathrm{~mL} \mathrm{~g}_{\text {ceria }}^{-1}$. The average solid temperatures and integrated oxygen amounts per unit mass are reduced when decreasing the porosity of the ceria. A linear correlation between the porosity and oxygen yield is observed, resulting from reduced heat loss with increasing porosity and raising temperature. In the subsequent oxidation step, the hydrogen production rate is extremely fast at the beginning when the water vapor enters the reactor. A temperature drop appears at the same time. The oxidation reaction is accomplished when the integral of generated hydrogen is twice the volume of oxygen, and the average solid temperature remains at ambient temperature. Typically, the oxidation is finished after 200 s. Overall, with the increasing porosity, the fuel yield is enhanced, owing to the extended absorbed radiation heat, leading to a higher solid average temperature, and the solar chemistry is boosted. However, in fixed-bed reactor, the produced fuel will be associated to the reactive material loading. The trend of fuel productivity changed when the mass 
loading was taken into account. The favored samples required porosities in the range of $\varepsilon=0.6-0.75$, attributing to heavier mass loading compared to the samples with higher porosity, although the productivity per unit mass was smaller.

\subsection{Effect of operational condition}

A set of parametric studies was conducted by varying operational conditions (concentration ratio, oxygen partial pressure fraction and inflow mass flow rate), one at a time. The cycle time was reduced to 15 minutes of reduction and 15 minutes of oxidation and the analysis is done for one complete cycle. With higher concentration ratios, the overall average temperature increased, resulting in a higher fuel output. The oxygen production rate for $C$ $=300$ was uniform and around $0.0015 \mathrm{~mL} \mathrm{~s}^{-1} \mathrm{~g}_{\text {ceria }}^{-1}$. For $C=600$, the oxygen rate raises maximally to $0.011 \mathrm{~mL} \mathrm{~s}^{-1} \mathrm{~g}_{\text {ceria }}^{-1}$ at $115 \mathrm{~s}$ and then drops off. For $C=750$, it reaches a maximum rate of $0.025 \mathrm{~mL} \mathrm{~s}^{-1} \mathrm{~g}_{\text {ceria }}^{-1}$ at 50s. During the oxidation step, the reduced ceria is oxidized instantly (typically within less than $200 \mathrm{~s}$ ). The hydrogen generation rate increases rapidly with the declining temperature. The maximum $\mathrm{H}_{2}$ generation rates are $0.665,0.488$ and $0.161 \mathrm{~mL} \mathrm{~s}^{-1} \mathrm{~g}_{\text {ceria }}^{-1}$ for $C=750,600$ and 300, respectively.

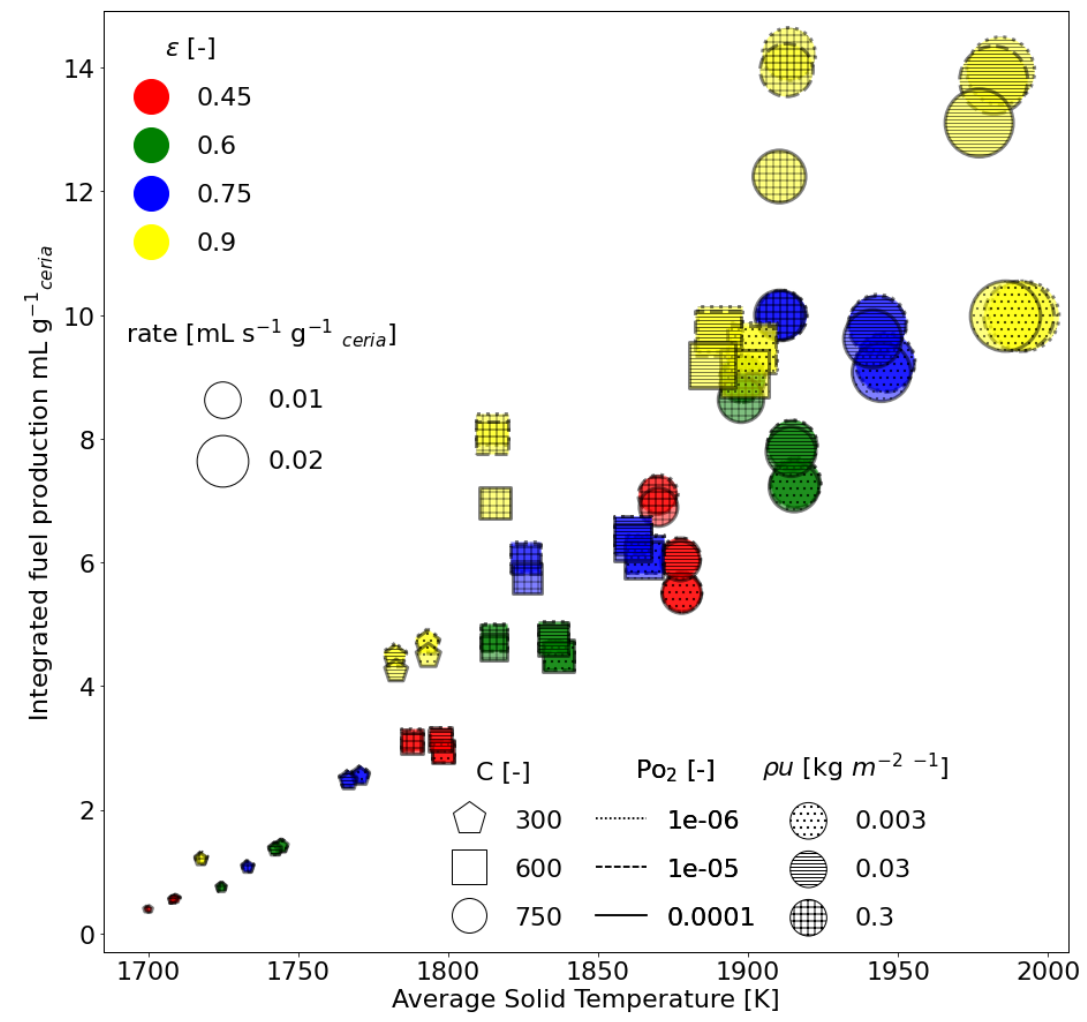

Figure 5. The integrated $\mathrm{H}_{2}$ production and the overall average solid temperature during the redox process for all the possible combinations of operational conditions for four representative porosities: $\varepsilon=0.45,0.60,0.75,0.90$. The color of the markers distinguishes the porosities, the shape represents the solar concentration ratio, the texture implies the fluid flow rate $\rho u$, the edge type reveals the initial $\mathrm{O}_{2}$ partial pressure fraction $\mathrm{Pp}_{\mathrm{O}_{2}}$, and the size indicates the maximum $\mathrm{O}_{2}$ generation rate. 
The impact of the initial $\mathrm{O}_{2}$ partial pressure was most significant when varying it between $10^{-4}$ and $10^{-5}$. A further decrease to $10^{-6}$ did not lead to significant further improvements. Similar trends are also observed in system efficiency studies [5] where a limited system efficiency benefit is observed given by the additional work required to reduce the partial pressure. Therefore, a value of $10^{-5}$ for oxygen partial pressure fraction is chosen for the following consideration. An increasing mass flow rate (between 0.003 and $0.3 \mathrm{kgm}^{-2} \mathrm{~s}^{-1}$ ) generally resulted in improved fuel productions (clearly for $C=750$ ). While in the initial duration of the reduction step, larger flow rates resulted in smaller oxygen production, the opposite was observed towards the end of the reduction step, where the fastest flow rates resulted in the largest integrated oxygen production. The large flow rates lead to a reduced average solid temperature, penalizing the production rates. However, towards steady state, the flow rate is limiting the production, favoring a faster flow rate, which facilitates the mass diffusion of gases. [20,52]

The complete dataset of the effect of porosity, irradiation concentration, flow rate, and oxygen partial pressure fraction on hydrogen production and average solid temperature is shown in Figure 5. Generally, it is noticed that for the scenarios with smallest production rates, we also observed the lowest overall mean temperature and integrated production. We also observe that high porosities and large irradiation concentrations lead to large solid temperatures, large integrated hydrogen production and also large hydrogen production rates. Furthermore, compared to temperature, the effect of oxygen partial pressure and inflow mass rate is less important, but potentially important in few specific cases (for example, among all the possible compositions, the sample with $\varepsilon=0.90$ at $C=750$ shows the best performance). However dependent on the flow velocity, higher temperatures but lower integrated hydrogen amounts are observed or the opposite, both relatively independent of the choice of oxygen partial pressure. For $\rho u=0.003\left[\mathrm{~kg} \mathrm{~m}^{-2} \mathrm{~s}^{-1}\right]$, the highest average temperature $(>1950 \mathrm{~K})$ and maximum $\mathrm{O}_{2}$ generation rate $(0.0207$ $\mathrm{mL} \mathrm{s}^{-1} \mathrm{~g}_{\text {ceria }}^{-1}$ ) were observed while the integrated hydrogen production was $9.893 \mathrm{~mL} \mathrm{~g}_{\text {ceria }}^{-1}$ only. For $\rho u=0.3\left[\mathrm{~kg} \mathrm{~m}^{-2} \mathrm{~s}^{-1}\right]$, the highest integrated hydrogen production of 14.2 $\mathrm{mL} \mathrm{g}_{\text {ceria }}^{-1}$ was observed while the average temperature was $1924 \mathrm{~K}$ and the $\mathrm{O}_{2}$ generation rate $0.0153 \mathrm{~mL} \mathrm{~s}^{-1} \mathrm{~g}_{\text {ceria }}^{-1}$. Similar trends were observed for the lower porosity samples, were the effect of mass flow is even more important. However, it is not the case anymore for lower concentration ratios $C$. In the subset of $C=600$, a reverse behavior is observed. Among all the samples, the most preferred flow rate is $\rho u=0.03 \mathrm{kgm}^{-2} \mathrm{~s}^{-1}$, both in terms of oxygen generation rate and the total $\mathrm{H}_{2}$ amount, although the average solid temperature is not the highest. And in the subset of $C=300$, we observed that the favorable flow rate switches to $\rho u=0.003 \mathrm{kgm}^{-2} \mathrm{~s}^{-1}$, where the average solid temperature is the maximal. Our observations show that porosity and operating conditions (especially concentration and 
mass flow rate) lead to a coupled interplay that needs to be carefully matched and controlled for optimized performance.

\subsection{Effect of non-uniform porosity distribution}

To study the impact of various porosity distributions on the fuel production behavior, we implemented functions with different $k$ in the available range as listed in the Table 1. And for each distribution scenario, we conducted one complete cycle under the same operation condition: $C=300, \rho u=0.03 \mathrm{kgm}^{-2} \mathrm{~s}^{-1}, P_{\mathrm{O}_{2}}=10^{-5}$, with 10 minutes of reduction and 10 minutes of oxidation. The hydrogen and oxygen production amounts and temperatures are shown in Figure 6 for reduction and oxidation cycles. For each non-uniformity case, two representative scenarios are shown, namely the scenarios that lead to the maximum and the minimum production in the selected ranges of $k$ (Table 1). In general, we observed that the temperature is a rough indication of the integrated fuel production when comparing the gradient cases within the same function category. Typically, the temperature distribution at steady state showed a hotter core temperature and a temperature gradient towards the boundary. This was true for the uniform as well as non-uniform porosity cases. However, for the latter in the best performing cases (i.e. non-uniform porosity distributions with a denser core and higher porosity boundaries), the average solid temperature was typically larger and the temperature gradient zones towards the boundary typically smaller compared to the uniform porosity cases. Higher porosity at the boundary allowed for better radiation penetration into the solid resulting in higher average temperatures and higher fuel yields. Increased porosity boundaries reduced the emission losses from the solid structure and reduced conduction towards the boundary, effectively insulating the core of the reactor. In addition, the structure with more pores on both boundaries (front and back) were preferred compared to the structure with higher porosities towards only one of the boundary (the front boundary). The latter indicated that radiation losses due to emission from the solid front side to the environment was more important than the radiation losses on the back side and that the gain from radiation absorption weighs more than the radiation loss by emission. The non-uniform distribution functions $f_{3}, f_{4}, f_{5}$ did not show significantly better performance than the uniform case. This could be explained by the fact that those structures have smaller gradients in the axial porosity, and a uniform-similar porosity distribution is observed. Among the various distribution functions, the most interesting configurations are $f_{2}$ and $f_{6}$, i.e. a symmetric design where both boundaries are more porous than the center zone. 
a.

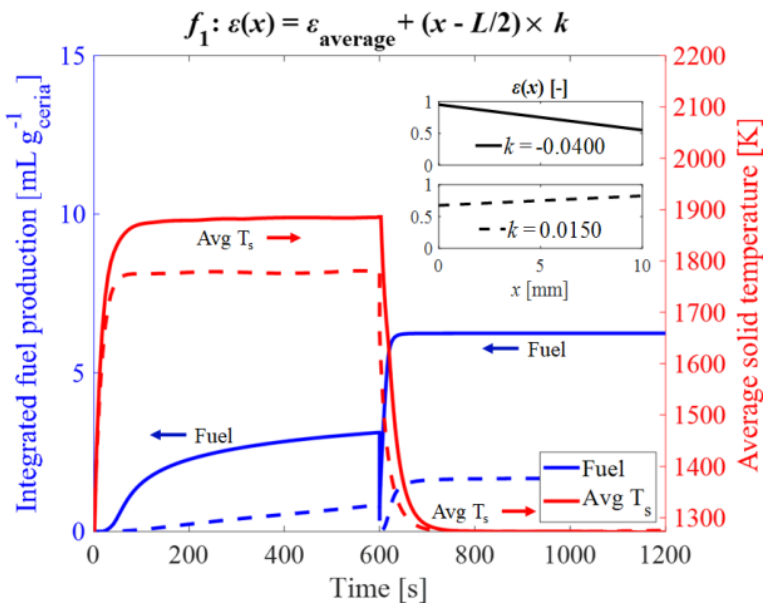

c.

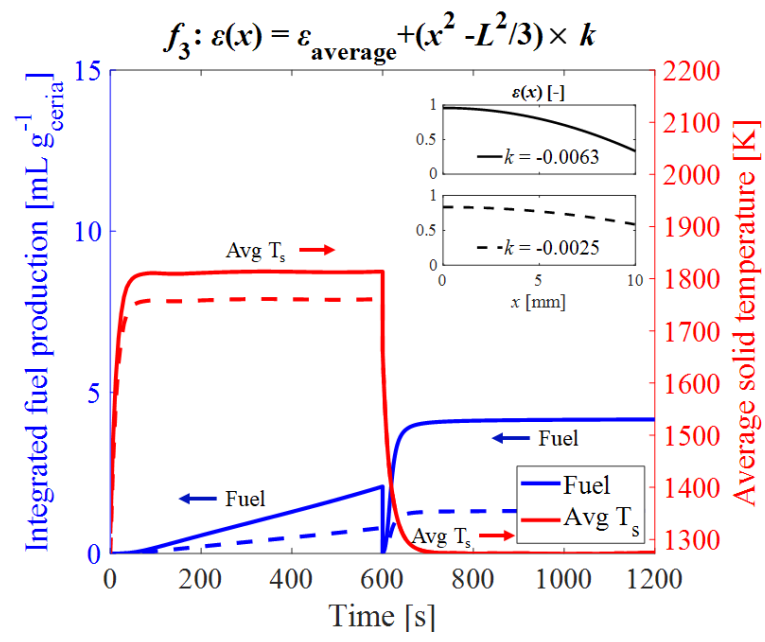

e.

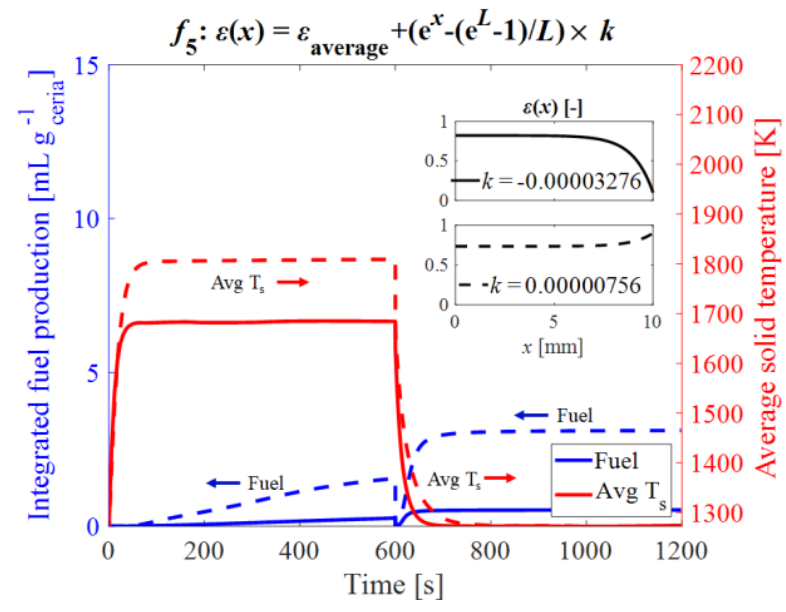

b.

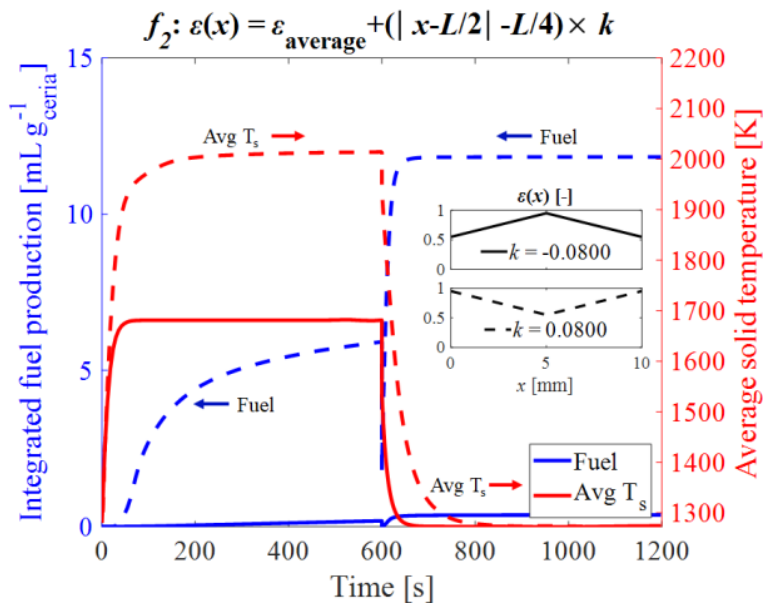

d.

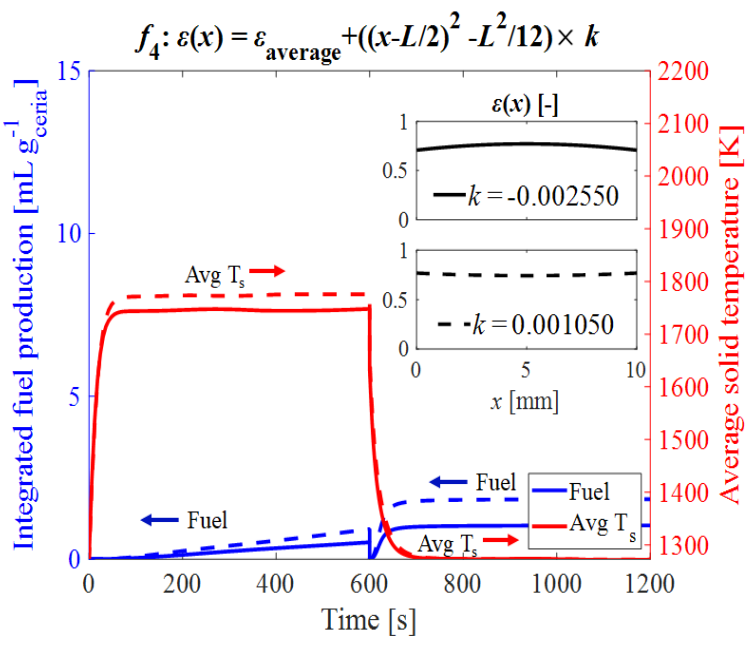

f.

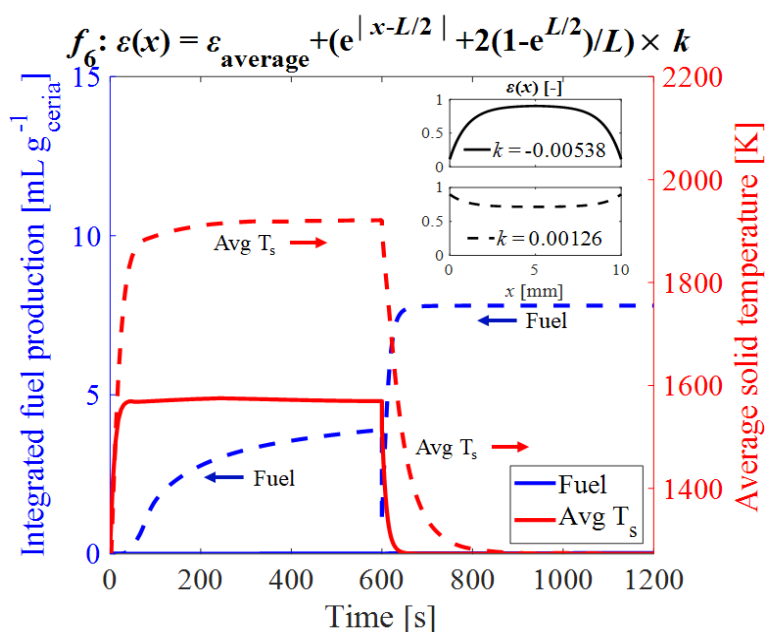

Figure 6. Evolution of fuel generation (blue) and average solid temperature (red) as a function of operational time for a complete cycle for samples with different non-uniform porosity distribution designs. The best (dotted) and worst (solid) performing distribution (in terms of production) for each distribution function is shown. $a$. $f_{1}: \varepsilon(x)=\varepsilon_{\text {average }}+k \times(x-L / 2) \quad ; \quad$ b. $\quad f_{2}: \varepsilon(x)=\varepsilon_{\text {average }}+k \times(|x-L / 2|-L / 4) \quad ; \quad c . \quad f_{3}: \varepsilon(x)=\varepsilon_{\text {average }}+k \times\left(x^{2}-L^{2} / 3\right) \quad ; \quad d$. $f_{4}: \varepsilon(x)=\varepsilon_{\text {average }}+k \times\left((x-L / 2)^{2}-L^{2} / 12\right) ; e . \quad f_{5}: \varepsilon(x)=\varepsilon_{\text {average }}+k \times\left(e^{x}-\left(e^{L}-1\right) / L\right) ; f . \quad f_{6}: \varepsilon(x)=\varepsilon_{\text {average }}+k \times\left(e^{|x-L / 2|}+2\left(1-e^{L / 2}\right) / L\right)$. 


\subsection{Effect of cycle duration}

The cyclic production of oxygen and hydrogen is presented in Figure 7 for ceria samples of $75 \%$ porosity at reference conditions and for different cycle durations with an overall production time of $7200 \mathrm{~s}$ (or 2 hours). The reduction and oxidation times are chosen equal. This ensures that the total solar energy input is identical for all the scenarios (same length of reduction duration). For each cycle, the produced $\mathrm{H}_{2}$ amount is double the produced $\mathrm{O}_{2}$ amount. Note that an initial training cycle was added that ensures that the successive cycling process is stable and repeatable. The integrated fuel production is shown in Figure 7 and shows that very short cycles (for example $t_{\text {cycle }}=60 \mathrm{~s}$ ) typically have inferior fuel production since time is required to heat up the solar reactor. With increasing cycle duration, the fuel production raises as the reactor operates at higher temperatures and can be operated closer to steady state. However, for scenarios with cycle durations longer than about $t_{\text {cycle }}=600 \mathrm{~s}$, the fuel production reaches a plateau and additional operational time doesn't significantly improve the fuel production (i.e. the fuel production is limited by available oxygen vacancies at the near steady state temperature and oxygen partial pressure). This indicates that a large amount of solar energy is used less efficiently, production rates are lower compared to the initial phase, limiting the solar-to-fuel efficiency.

The best compromise that enables a reactor temperature high enough for considerable production rates while not long enough to lead to inefficient use of the input energy depends on the chosen porosity (see Figure 7-ii). Therefore, finding a proper cycling duration time for a given porosity is necessary to improve the overall fuel production and optimize the energy conversion efficiency. Very short or very long cycles were not favored. $\varepsilon=0.90$ showed the best performance at an optimal cycle duration of $t_{\text {cycle }}=240 \mathrm{~s}$, with a total fuel production of $174.82 \mathrm{~mL} \mathrm{~g}_{\text {ceria }}^{-1}$. At $\varepsilon=0.75$, the best total fuel production of $115.78 \mathrm{~mL} \mathrm{~g}_{\text {ceria }}^{-1}$ was also achieved at $t_{\text {cycle }}=240 \mathrm{~s}$. Samples with lower porosity favored longer cycle durations with $t_{\text {cycle }}=300 \mathrm{~s}$ showed best performance for $\varepsilon=0.6$ and $t_{\text {cycle }}=600 \mathrm{~s}$ for $\varepsilon=0.45$, with total output of $\mathrm{H}_{2}$ of 79.36 and $45.95 \mathrm{~mL} \mathrm{~g}_{\text {ceria }}^{-1}$, respectively. In the cases with lower temperatures, the evolution of the generation rate is slower compared to the porous cases with high temperatures. By modulating the cycle time, a higher fuel output is reached. For porosity $\varepsilon=0.75$, around six times more hydrogen is produced for the optimized cycling duration of $t_{\text {cycle }}=240 \mathrm{~s}$ than the one produced in the shortest or the longest cycle. 
i.

a.
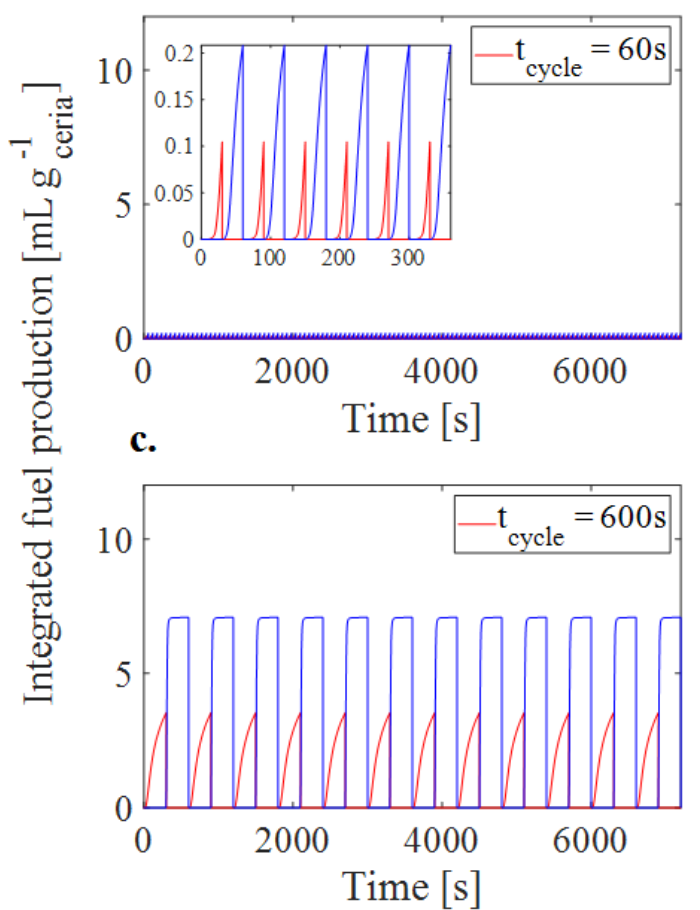

b.
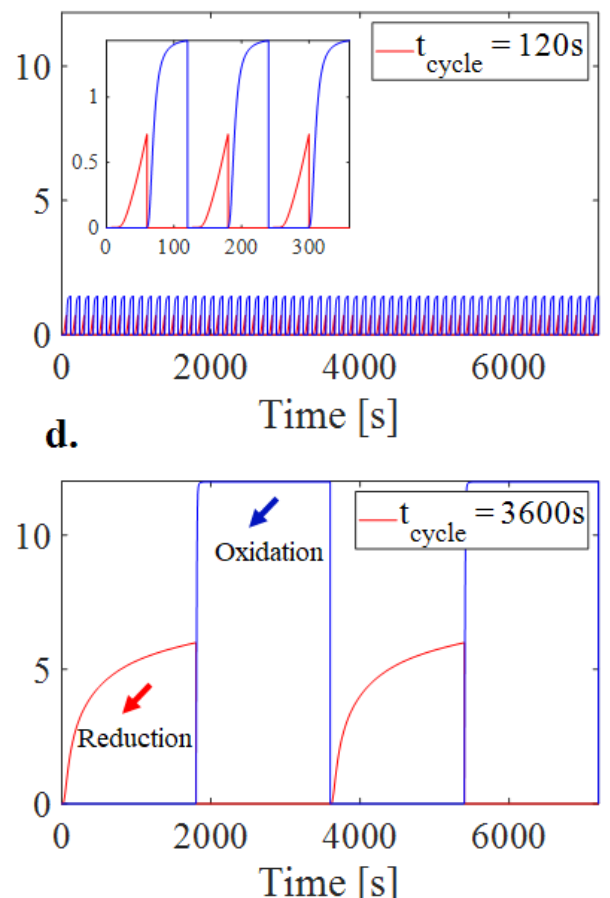

ii.

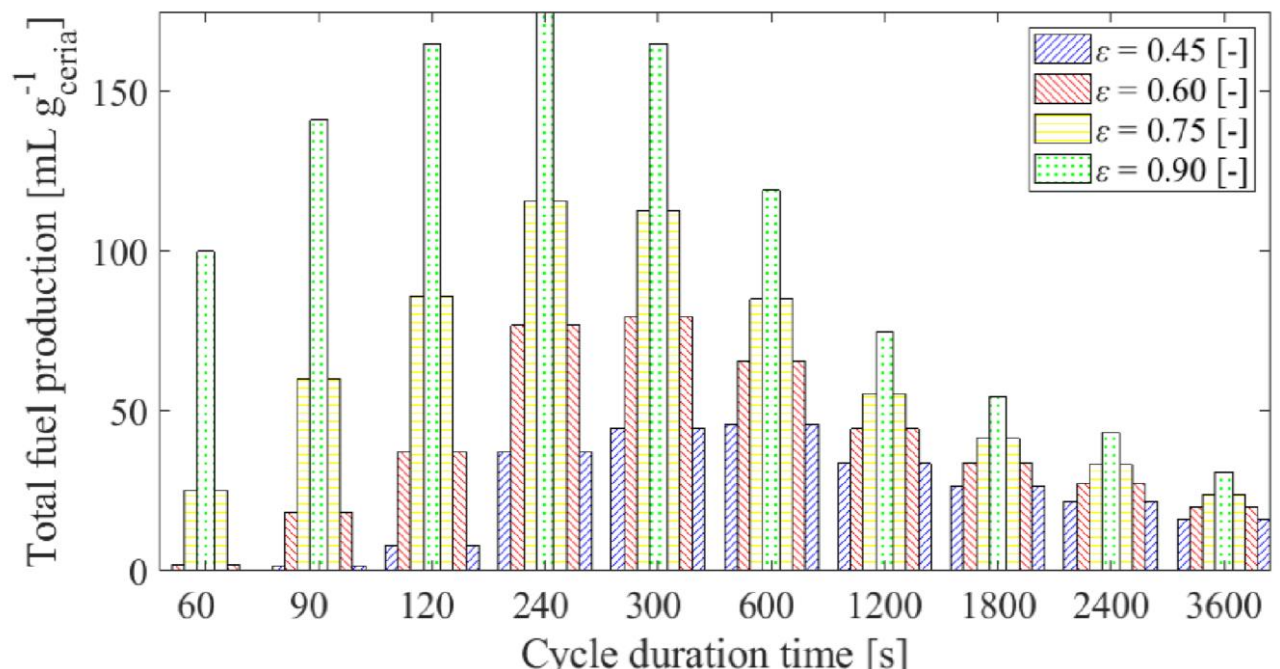

Figure 7-i. Cyclic behavior of reference scenarios for two hours operating time with different cycling durations: a) $t$ $=60, b) t=120, c) t=600, d) t=3600$ s, all for porosity of $75 \%$ and reference conditions (i.e. $C=750, P_{\mathrm{O}_{2}}=10^{-5}$ and inflow mass of $\left.\rho u=0.03 \mathrm{kgm}^{-2} \mathrm{~s}^{-1}\right)$. ii. The total $\mathrm{H}_{2}$ production for a two-hour operation as a function of individual cycle duration for four different porosities. 
a.

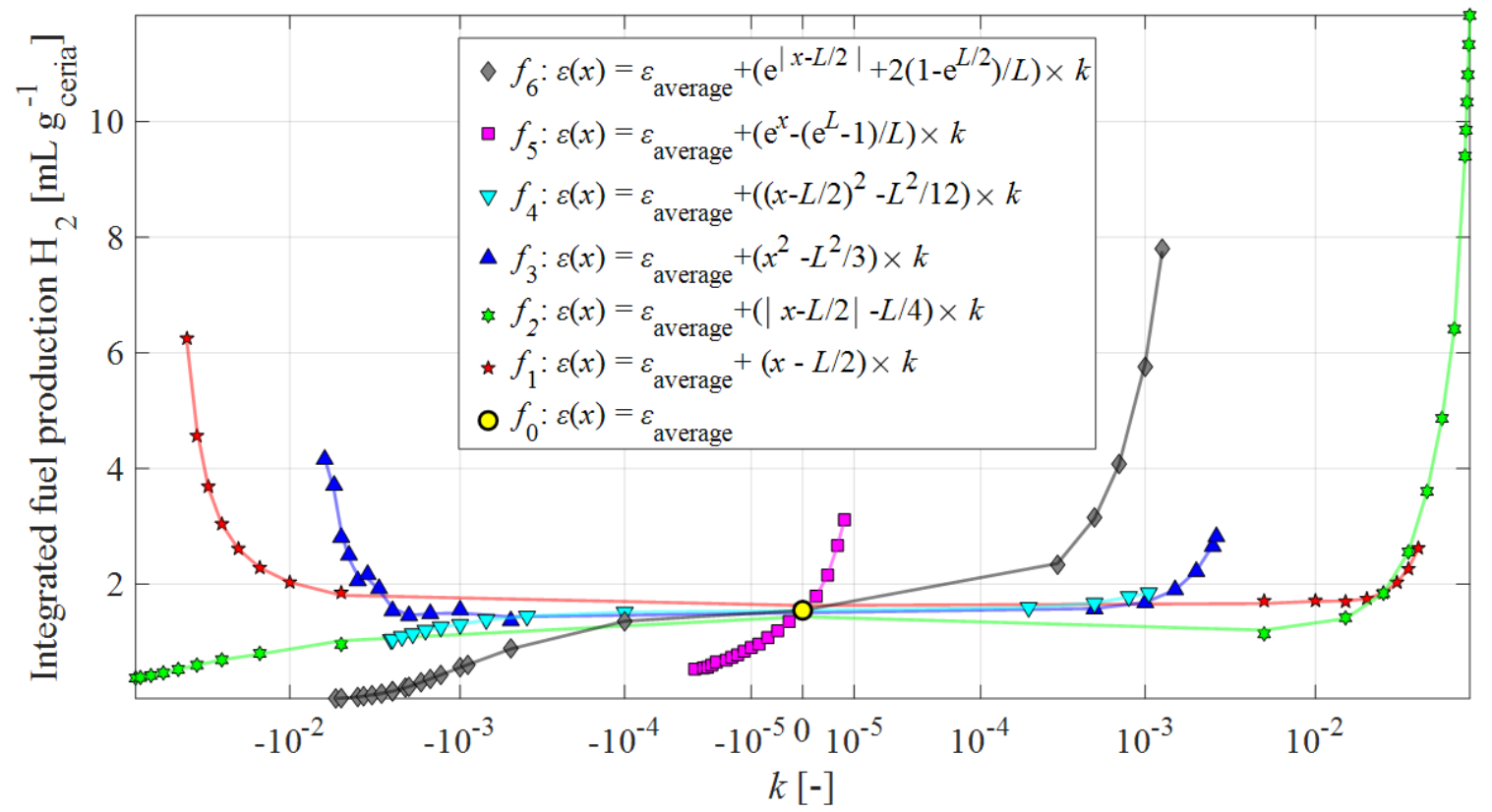

b.

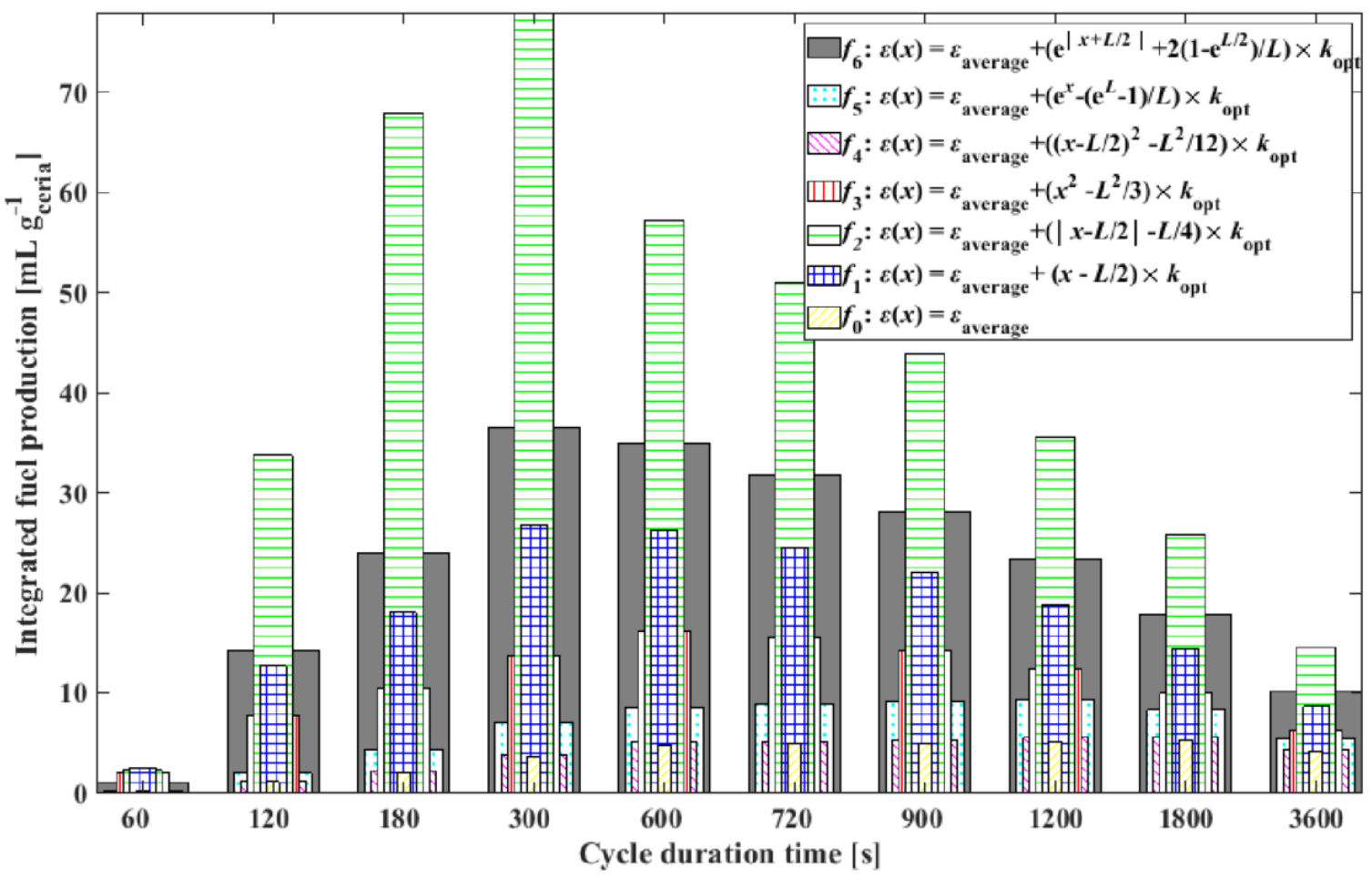

Figure 8. a) Integrated hydrogen produced for two-hour operation with a cycle duration of 600s, concentration C=300 for the different non-uniform porosity distributions of the ceria with changing gradients, $k . b$ ) The total $\mathrm{H}_{2}$ production for two-hour operation as a function of individual cycle duration for four different porosity distributions at operation condition (i.e. $C=300^{P_{\mathrm{O}_{2}}}=10^{-5}$ and inflow mass of $\rho u=0.03 \mathrm{kgm}^{-2} \mathrm{~s}^{-1}$ ).

Figure 8a summarizes the benefit of non-uniform porosity distributions on the fuel production, specifically also in comparison to the uniform case. In comparison with the 
uniform scenario, the total produced $\mathrm{H}_{2}$ is increased only if a proper gradient direction (positive or negative) and strength was chosen. If wrongly chosen, a reduction in the amount of produced fuel was observed compared to the uniform case. When applying an appropriate distribution, a six-fold increase in fuel production was reached compared to the uniform structure. This increase could be further enhanced when the cycle duration was adapted (see Figure 8b). While for the uniform structure the highest output was 5.31 $\mathrm{mL} \mathrm{g}_{\text {ceria }}^{-1}$ at $t=1800 \mathrm{~s}$, the more productive porosity distributions (i.e. $f_{1}, f_{2}, f_{6}$ ) required typically shorter cycle duration for increased production. The most productive sample was with a porosity distribution of $f_{2}$, with a cycle duration of $300 \mathrm{~s}$ exhibiting a total fuel output of $77.96 \mathrm{~mL} \mathrm{~g}_{\text {ceria }}^{-1}, 14.6$ times higher than the uniform structure under the best cycle duration. The non-uniform function sets $f_{3}, f_{4}, f_{5}$ are found to be more similar to the uniform cases in terms of required cycle time. This is due to the small gradient of porosity change within the structure. The enhancement of fuel yield was at least 3 times more by modulating the cycle duration time for the porosity distributions $f_{1}, f_{2}, f_{6}$.

\section{Summary and conclusion}

We implemented a one-dimensional transient heat and mass transfer model to characterize a solar-driven thermochemical fixed-bed redox water splitting reactor during reduction and oxidation steps.

We study the combinational effect of operating condition, morphology (i.e. porosity and porosity distribution) and cycle duration. In general, higher solar concentration ratios and a lower $\mathrm{O}_{2}$ partial pressures lead to higher fuel production. The effect of mass flow rate needs to be considered together with the concentration ratio as two regions with opposite behavior are observed. Operation at a high concentration ratio results in a high average solid temperature and higher fuel yields, but is limited by the mass flow rate. At a low concentration ratio, the role of the solid temperature is more important than the mass flow rate. However, the increase of concentration ratio and the decrease of the oxygen partial pressure both require extra work input, which might not necessarily improve the total system-level fuel conversion efficiency.

For constant operation condition and constrained material mass loading, non-homogeneous porous structures were considered, i.e. structures with different non-uniform porosity distributions. The optimized structures were the ones with more void space on both boundaries and more solid space in the central zone of the reactor. Six-fold increase in fuel production can be achieved when changing from uniform to optimized non-uniform porosity samples.

The cycle duration is another vital factor to affect the solar-to-fuel efficiency. By modulating and optimizing the cycle duration for different porosity samples, more fuel was produced for the same amount of energy input. Combining non-uniform porosity with 
optimized cycle duration, an enhancement in fuel production was pushed to 14.6 times improvement.

In conclusion, in order to improve the fuel production performance for a fixed-bed solardriven thermochemical reactor, a combination of non-uniform porosity and cycle duration optimization needs to be considered.

\section{Acknowledgements}

We thank the fruitful discussion with Prof. Daniel Keene, Seattle Pacific University, on the kinetic rate modelling, and Prof. Meng Lin, former EPFL and now Southern University of Science and Technology, for discussion on numerical modeling.

\section{Nomenclature}

\section{Latin Symbols}

$A_{0}=$ specific surface area, $\left[\mathrm{m}^{-1}\right]$

$c_{\mathrm{p}}=$ heat capacity, $[\mathrm{W} / \mathrm{kg} / \mathrm{K}]$

$C=$ solar irradiation concentration, [-]

$d_{\text {mean }}=$ pore diameter, $[\mathrm{m}]$

$D=$ gas diffusion coefficient, $\left[\mathrm{m}^{2} / \mathrm{s}\right]$

$f=$ non-uniform porous distribution function, [-]

$F_{\mathrm{D}}=$ Dupuit-Forchheimer coefficient, $\left[\mathrm{m}^{-1}\right]$

$\Delta G=$ Gibbs free energy difference, $[\mathrm{J}]$

$h_{\mathrm{sf}}=$ solid-fluid interfacial heat transfer coefficient, $[\mathrm{W} / \mathrm{m} / \mathrm{K}]$

$\Delta H=$ enthalpy difference, $[\mathrm{J}]$

$k=$ gradient, [-]

heat conductivity, $[\mathrm{W} / \mathrm{m} / \mathrm{K}]$

$K=$ permeability, $\left[\mathrm{m}^{2}\right]$

$L, L=$ length, [m]

$M=$ molar mass, $[\mathrm{kg} / \mathrm{mol}]$

$n=$ kinetic rate constant, $\left[\mathrm{mol} / \mathrm{m}^{2} / \mathrm{s}\right]$

$\mathrm{Nu}=$ Nusselt number, [-]

$p=$ pressure, $[\mathrm{Pa}]$

$P_{\mathrm{O}_{2}}=\mathrm{O}_{2}$ partial pressure fraction, [-]

$\operatorname{Pr}=$ Prandlt number, [-]

$Q_{\text {rad }}=$ radiative flux, $\left[\mathrm{W} / \mathrm{m}^{2}\right]$

$Q_{\text {reaction }}=$ reaction heat source term, $\left[\mathrm{W} / \mathrm{m}^{3}\right]$

$r_{\mathrm{O}_{2}}=$ oxygen evolution rate, $\left[\mathrm{kg} / \mathrm{m}^{3} / \mathrm{s}\right]$

$R=$ ideal gas constant, $8.31446[\mathrm{~J} / \mathrm{K} / \mathrm{mol}]$

$\operatorname{Re}=$ Reynold number, $[-]$ 
$\Delta S=$ entropy difference, $[\mathrm{J}]$

$t=$ time, $[\mathrm{s}]$

$T=$ temperature, $[\mathrm{K}]$

$u=$ flow velocity, $[\mathrm{m} / \mathrm{s}]$

$\mathrm{V}=$ ceria volume, $\left[\mathrm{m}^{3}\right]$

$x=$ local position, $[\mathrm{m}]$

$Y=$ species mass fraction, [-]

\section{Greek Symbols}

$\beta=$ extinction coefficient, $\left[\mathrm{m}^{-1}\right]$

$\delta=$ nonstoichiometry, [-]

$\mu_{\mathrm{f}}=$ fluid dynamic viscosity, [Pa.s]

$\rho=$ density, $\left[\mathrm{kg} / \mathrm{m}^{3}\right]$

$\sigma_{\mathrm{B}}=$ Boltzmann constant, $1.38065 \mathrm{e}^{-23}\left[\mathrm{~m}^{2} \mathrm{~kg} / \mathrm{s}^{2} / \mathrm{K}\right]$

$\varepsilon=$ porosity, $[-]$

\section{Subscripts}

$\mathrm{s}=$ solid

$\mathrm{f}=$ fluid

$i=$ specie, $\mathrm{O}_{2}, \mathrm{H}_{2}, \mathrm{H}_{2} \mathrm{O}, \mathrm{Ar}$

in $=$ inlet

$\mathrm{amb}=\mathrm{ambient}$

red $=$ reduction

oxi $=$ oxidation

ref $=$ reference

\section{Abbreviation}

CR5 = Counter-Rotating-Ring Receiver Reactor Recuperator

3DOM = Three-Dimensionally Ordered Macro-porous

$\mathrm{RPC}=$ Reticulate Porous Ceria

$1 \mathrm{D}=$ One-Dimensional

\section{References}

[1] W.C. Chueh, S.M. Haile, Ceria as a thermochemical reaction medium for selectively generating syngas or methane from $\mathrm{H} 2 \mathrm{O}$ and $\mathrm{CO} 2$, ChemSusChem. 2 (2009) 735-739. https://doi.org/10.1002/cssc.200900138.

[2] R.J. Panlener, R.N. Blumenthal, J.E. Garnier, A thermodynamic study of nonstoichiometric cerium dioxide, J. Phys. Chem. Solids. 36 (1975) 1213-1222. https://doi.org/10.1016/0167-2738(93)90006-O. 
[3] M. Zinkevich, D. Djurovic, F. Aldinger, Thermodynamic modelling of the ceriumoxygen system, Solid State Ionics. 177 (2006) 989-1001. https://doi.org/10.1016/j.ssi.2006.02.044.

[4] A. Le Gal, S. Abanades, G. Flamant, $\mathrm{CO} 2$ and $\mathrm{H} 2 \mathrm{O}$ splitting for thermochemical production of solar fuels using nonstoichiometric ceria and ceria/zirconia solid solutions, Energy and Fuels. 25 (2011) 4836-4845.

[5] M. Lin, S. Haussener, Solar fuel processing efficiency for ceria redox cycling using alternative oxygen partial pressure reduction methods, Energy. 88 (2015) 667-679. https://doi.org/10.1016/j.energy.2015.06.006.

[6] P. Furler, Solar Thermochemical CO2 and H2O Splitting via Ceria Redox Reactions, 2014. https://doi.org/http://dx.doi.org/10.3929/ethz-a-010207593.

[7] A. Haeussler, S. Abanades, A. Julbe, J. Jouannaux, B. Cartoixa, Solar thermochemical fuel production from $\mathrm{H} 2 \mathrm{O}$ and $\mathrm{CO} 2$ splitting via two-step redox cycling of reticulated porous ceria structures integrated in a monolithic cavity-type reactor, Energy. 201 (2020). https://doi.org/10.1016/j.energy.2020.117649.

[8] C. Jarrett, W. Chueh, C. Yuan, Y. Kawajiri, K.H. Sandhage, A. Henry, Critical limitations on the efficiency of two-step thermochemical cycles, Sol. Energy. 123 (2016) 57-73. https://doi.org/10.1016/j.solener.2015.09.036.

[9] S. Ackermann, M. Takacs, J. Scheffe, A. Steinfeld, Reticulated porous ceria undergoing thermochemical reduction with high-flux irradiation, Int. J. Heat Mass Transf. 107 (2017) 439-449. https://doi.org/10.1016/j.ijheatmasstransfer.2016.11.032.

[10] D.J. Keene, J.H. Davidson, W. Lipiński, A Model of Transient Heat and Mass Transfer in a Heterogeneous Medium of Ceria Undergoing Nonstoichiometric Reduction, J. Heat Transfer. 135 (2013) 052701. https://doi.org/10.1115/1.4023494.

[11] P. Furler, J.R. Scheffe, A. Steinfeld, Syngas production by simultaneous splitting of $\mathrm{H} 2 \mathrm{O}$ and $\mathrm{CO} 2$ via ceria redox reactions in a high-temperature solar reactor, Energy Environ. Sci. 5 (2012) 6098. https://doi.org/10.1039/c1ee02620h.

[12] W.C. Chueh, C. Falter, M. Abbott, D. Scipio, P. Furler, S.M. Haile, A. Steinfeld, High-flux solar-driven thermochemical dissociation of $\mathrm{CO} 2$ and $\mathrm{H} 2 \mathrm{O}$ using nonstoichiometric ceria, Science (80-. ). 330 (2010) 1797-1801. https://doi.org/10.1126/science.1197834.

[13] C.L. Muhich, B.W. Evanko, K.C. Weston, P. Lichty, X. Liang, J. Martinek, C.B. Musgrave, A.W. Weimer, Efficient Generation of $\mathrm{H} 2$ by Spiltting Water with an Isothermal Redox Cycle, Science (80-. ). 341 (2013) 540-543.

[14] L.J. Venstrom, R.M. De Smith, Y. Hao, S.M. Haile, J.H. Davidson, Efficient Splitting of $\mathrm{CO} 2$ in an Isothermal Redox Cycle Based on Ceria, Energy and Fuels. 28 (2014) 2732-2742.

[15] T.C. Davenport, C.K. Yang, C.J. Kucharczyk, M.J. Ignatowich, S.M. Haile, Maximizing fuel production rates in isothermal solar thermochemical fuel production, Appl. Energy. 183 (2016) 1098-1111. https://doi.org/10.1016/j.apenergy.2016.09.012. 
[16] T.C. Davenport, M. Kemei, M.J. Ignatowich, S.M. Haile, Interplay of material thermodynamics and surface reaction rate on the kinetics of thermochemical hydrogen production, Int. J. Hydrogen Energy. 42 (2017) 16932-16945. https://doi.org/10.1016/j.ijhydene.2017.05.184.

[17] T.C. Davenport, C.K. Yang, C.J. Kucharczyk, M.J. Ignatowich, S.M. Haile, Implications of Exceptional Material Kinetics on Thermochemical Fuel Production Rates, Energy Technol. 4 (2016) 764-770. https://doi.org/10.1002/ente.201500506.

[18] R.B. Diver, J.E. Miller, N.P. Siegel, T.A. Moss, Testing of a CR5 Solar Thermochemical Heat Engine Prototype, ASME 2010 4th Int. Conf. Energy Sustain. 2 (2010). https://doi.org/10.1115/ES2010-90093.

[19] M. Roeb, M. Neises, J.P. Säck, P. Rietbrock, N. Monnerie, J. Dersch, M. Schmitz, C. Sattler, Operational strategy of a two-step thermochemical process for solar hydrogen production, Int. J. Hydrogen Energy. 34 (2009) 4537-4545. https://doi.org/10.1016/j.ijhydene.2008.08.049.

[20] P. Furler, A. Steinfeld, Heat transfer and fluid flow analysis of a $4 \mathrm{~kW}$ solar thermochemical reactor for ceria redox cycling, Chem. Eng. Sci. 137 (2015) 373383. https://doi.org/10.1016/j.ces.2015.05.056.

[21] R. Bader, R. Bala Chandran, L.J. Venstrom, S.J. Sedler, P.T. Krenzke, R.M. De Smith, A. Banerjee, T.R. Chase, J.H. Davidson, W. Lipiński, Design of a Solar Reactor to Split CO 2 Via Isothermal Redox Cycling of Ceria, J. Sol. Energy Eng. 137 (2015) 031007. https://doi.org/10.1115/1.4028917.

[22] A. Haeussler, S. Abanades, J. Jouannaux, M. Drobek, A. Ayral, A. Julbe, Recent progress on ceria doping and shaping strategies for solar thermochemical water and CO2 splitting cycles, AIMS Mater. Sci. 6 (2019) 657-684. https://doi.org/10.3934/MATERSCI.2019.5.657.

[23] R.C. Pullar, R.M. Novais, A.P.F. Caetano, M.A. Barreiros, S. Abanades, F.A.C. Oliveira, A Review of Solar Thermochemical CO2 Splitting Using Ceria-Based Ceramics With Designed Morphologies and Microstructures, Front. Chem. 7 (2019). https://doi.org/10.3389/fchem.2019.00601.

[24] Q.L. Meng, C. Il Lee, S. Shigeta, H. Kaneko, Y. Tamaura, Solar hydrogen production using Ce 1-xLi xO $2-\delta$ solid solutions via a thermochemical, two-step water-splitting cycle, J. Solid State Chem. 194 (2012) 343-351. https://doi.org/10.1016/j.jssc.2012.05.024.

[25] R. Jacot, J.M. Naik, R. Moré, R. Michalsky, A. Steinfeld, G.R. Patzke, Reactive stability of promising scalable doped ceria materials for thermochemical two-step CO2 dissociation, J. Mater. Chem. A. 6 (2018) 5807-5816. https://doi.org/10.1039/c7ta10966k.

[26] L.J. Venstrom, N. Petkovich, S. Rudisill, A. Stein, J.H. Davidson, The effects of morphology on the oxidation of ceria by water and carbon dioxide, J. Sol. Energy Eng. Trans. ASME. 134 (2012) 1-8. https://doi.org/10.1115/1.4005119.

[27] P. Furler, J. Scheffe, M. Gorbar, L. Moes, U. Vogt, A. Steinfeld, Solar thermochemical $\mathrm{CO} 2$ splitting utilizing a reticulated porous ceria redox system, Energy and Fuels. 26 (2012) 7051-7059. https://doi.org/10.1021/ef3013757. 
[28] M. Takacs, S. Ackermann, A. Bonk, M.N. Puttkamer, P. Haueter, J.R. Scheffe, U.F. Vogt, A. Steinfeld, Splitting CO2 with a ceria-based redox cycle in a solardriven thermogravimetric analyzer, AIChE J. 00 (2016). https://doi.org/10.1002/aic.

[29] D.J. Keene, W. Lipiński, J.H. Davidson, The effects of morphology on the thermal reduction of nonstoichiometric ceria, Chem. Eng. Sci. 111 (2014) 231-143. https://doi.org/10.1016/j.ces.2014.01.010.

[30] R. Bala Chandran, R. Bader, W. Lipiński, Transient heat and mass transfer analysis in a porous ceria structure of a novel solar redox reactor, Int. J. Therm. Sci. 92 (2015) 138-149. https://doi.org/10.1016/j.ijthermalsci.2015.01.016.

[31] R. Bala Chandran, J.H. Davidson, Model of transport and chemical kinetics in a solar thermochemical reactor to split carbon dioxide, Chem. Eng. Sci. 146 (2016) 302-315. https://doi.org/10.1016/j.ces.2016.03.001.

[32] R. Bala Chandran, R.M. De Smith, J.H. Davidson, Model of an integrated solar thermochemical reactor/reticulated ceramic foam heat exchanger for gas-phase heat recovery, Int. J. Heat Mass Transf. 81 (2015) 404-414. https://doi.org/10.1016/j.ijheatmasstransfer.2014.10.053.

[33] M.I. Roldán, O. Smirnova, T. Fend, J.L. Casas, E. Zarza, Thermal analysis and design of a volumetric solar absorber depending on the porosity, Renew. Energy. 62 (2014) 116-128. https://doi.org/10.1016/j.renene.2013.06.043.

[34] H. Zhu, B. V. Sankar, R.T. Haftka, S. Venkataraman, M. Blosser, Optimization of functionally graded metallic foam insulation under transient heat transfer conditions, Struct. Multidiscip. Optim. 28 (2004) 349-355. https://doi.org/10.1007/s00158-004-0463-3.

[35] Z. Zhan, J. Xiao, D. Li, M. Pan, R. Yuan, Effects of porosity distribution variation on the liquid water flux through gas diffusion layers of PEM fuel cells, J. Power Sources. 160 (2006) 1041-1048. https://doi.org/10.1016/j.jpowsour.2006.02.060.

[36] S.A. Grigoriev, P. Millet, S.A. Volobuev, V.N. Fateev, Optimization of porous current collectors for PEM water electrolysers, Int. J. Hydrogen Energy. 34 (2009) 4968-4973. https://doi.org/10.1016/j.ijhydene.2008.11.056.

[37] Y.S. Touloukian, Thermophysical properties of high temperature solid materials, 1967.

[38] E. Cussler, Diffusion: Mass transfer in fluid systems, 2009.

[39] M. Binnewies, Thermochemical data of elements and compounds, 2002.

[40] V. Chekhovskoy, G. Stravrovsky, Thermal conductivity of cerium dioxide, 9th Conf. Therm. Conduct. (1970).

[41] C. Yaws, Transport properties of chemicals and hydrocarbons: Viscosity, thermal conductivity, and diffusivity of $\mathrm{C} 1$ to $\mathrm{C} 100$ organics and Ac to $\mathrm{Zr}$ inorganics, 2009.

[42] T. Marrero, E.A. Mason, Gaseous diffusion coefficients, J.Phys.Chem.Ref.Data 1. (1972).

[43] S. Suter, A. Steinfeld, S. Haussener, Pore-level engineering of macroporous media for increased performance of solar-driven thermochemical fuel processing, Int. J. Heat Mass Transf. 78 (2014) 688-698. 
[44] S. Haussener, A. Steinfeld, Effective heat and mass transport properties of anisotropic porous ceria for solar thermochemical fuel generation, Materials (Basel). 5 (2012) 192-209. https://doi.org/10.3390/ma5010192.

[45] S. Ackermann, J.R. Scheffe, J. Duss, A. Steinfeld, Morphological characterization and effective thermal conductivity of dual-scale reticulated porous structures, Materials (Basel). 7 (2014) 7173-7195. https://doi.org/10.3390/ma7117173.

[46] P. Wang, K. Vafai, D.Y. Liu, Analysis of the volumetric phenomenon in porous beds subject to irradiation, Numer. Heat Transf. Part A Appl. 70 (2016) 567-580. https://doi.org/10.1080/10407782.2016.1192941.

[47] P. Wang, K. Vafai, D.Y. Liu, C. Xu, Analysis of collimated irradiation under local thermal non-equilibrium condition in a packed bed, Int. J. Heat Mass Transf. 80 (2015) 789-801. https://doi.org/10.1016/j.ijheatmasstransfer.2014.09.021.

[48] L.J. Venstrom, R.M. De Smith, R. Bala Chandran, D.B. Boman, P.T. Krenzke, J.H. Davidson, Applicability of an Equilibrium Model to Predict the Conversion of CO2 to $\mathrm{CO}$ via the Reduction and Oxidation of a Fixed Bed of Cerium Dioxide, Energy and Fuels. 29 (2015) 8168-8177. https://doi.org/10.1021/acs.energyfuels.5b01865.

[49] D.J. Keene, Numerical Modeling of Transport Phenomena in Reactive Porous Structures for Solar Fuel Applications, University of Minnesota, 2013.

[50] B. Bulfin, A.J. Lowe, K.A. Keogh, B.E. Murphy, O. Lübben, S.A. Krasnikov, I. V. Shvets, Analytical model of $\mathrm{CeO} 2$ oxidation and reduction, J. Phys. Chem. C. 117 (2013) 24129-24137. https://doi.org/10.1021/jp406578z.

[51] B. Bulfin, L. Hoffmann, L. De Oliveira, N. Knoblauch, F. Call, M. Roeb, C. Sattler, M. Schmücker, Statistical thermodynamics of non-stoichiometric ceria and ceria zirconia solid solutions, Phys. Chem. Chem. Phys. 18 (2016) 23147-23154. https://doi.org/10.1039/c6cp03158g.

[52] B.J. Hathaway, R.B. Chandran, S.J. Sedler, D. Thomas, A. Gladen, T.R. Chase, J.H. Davidson, R. Bala Chandran, S.J. Sedler, D. Thomas, A. Gladen, T.R. Chase, J.H. Davidson, Effect of Flow Rates on Operation of a Solar Thermochemical Reactor for Splitting CO2 Via the Isothermal Ceria Redox Cycle, J. Sol. Energy Eng. Trans. ASME. 138 (2016) 1-12. https://doi.org/10.1115/1.4032019. 